\title{
Immunogenetics
}

\section{Identification of the salmonid IL-17A/F1a/b, IL-17A/F2b, IL-17A/F3 and IL-17N genes and analysis of their expression following in vitro stimulation and infection. --Manuscript Draft--}

\begin{tabular}{|c|c|}
\hline Manuscript Number: & IMMU-D-15-00008R2 \\
\hline Full Title: & $\begin{array}{l}\text { Identification of the salmonid IL-17A/F1a/b, IL-1 } \\
\text { and analysis of their expression following in vitr }\end{array}$ \\
\hline Article Type: & Original Paper \\
\hline Keywords: & $\begin{array}{l}\text { IL-17A/F isoforms, IL-17N, expression, Atlantic } \\
\text { Oncorhynchus mykiss }\end{array}$ \\
\hline Corresponding Author: & $\begin{array}{l}\text { Christopher John Secombes, Bsc, PhD, DSc } \\
\text { University of Aberdeen } \\
\text { Aberdeen, Scotland UNITED KINGDOM }\end{array}$ \\
\hline \multicolumn{2}{|l|}{$\begin{array}{l}\text { Corresponding Author Secondary } \\
\text { Information: }\end{array}$} \\
\hline Corresponding Author's Institution: & University of Aberdeen \\
\hline \multicolumn{2}{|l|}{$\begin{array}{l}\text { Corresponding Author's Secondary } \\
\text { Institution: }\end{array}$} \\
\hline First Author: & Christopher John Secombes, Bsc, PhD, DSc \\
\hline \multicolumn{2}{|l|}{ First Author Secondary Information: } \\
\hline \multirow[t]{6}{*}{ Order of Authors: } & Christopher John Secombes, Bsc, PhD, DSc \\
\hline & Tiehui Wang, PhD \\
\hline & Yousheng Jiang, PhD \\
\hline & Alex Wang \\
\hline & Mansourah Husain, PhD \\
\hline & Qiaoqing $\mathrm{Xu}, \mathrm{PhD}$ \\
\hline
\end{tabular}

Order of Authors Secondary Information:

Funding Information:

\begin{tabular}{|c|c|}
\hline Abstract: & $\begin{array}{l}\text { This study identifies four new IL-17A/F isoforms in salmonids, as well as IL-17N. IL- } \\
17 \mathrm{~F} / \mathrm{F} 1 \text { and IL-17A/F2 are each represented by two paralogues, with a predicted } \\
\text { pseudogene of IL-17N also apparent in the salmonid genome. Analysis of the } \\
\text { sequences and genes of the known IL-17A/F and IL-17N molecules suggests that IL- } \\
17 \mathrm{~N} \text { is a member within the IL-17A/F subfamily. Analysis of factors that modulated the } \\
\text { expression of these genes showed that PHA and PMA were good inducers of salmon } \\
\text { IL-17A/F1a and IL-17A/F2a, with rIL-21 a potent stimulator of IL-17A/F1a and IL- } \\
17 \mathrm{~A} / \mathrm{F} 3 \text {. The potential involvement of these isoforms during responses post-vaccination } \\
\text { and infection was also studied. In unvaccinated control fish, Yersinia ruckeri infection } \\
\text { resulted in a marked up-regulation of IL-17A/F1a and IL-17N in spleen and head } \\
\text { kidney, and IL-17A/F2a and IL-17A/F3 in spleen. In the vaccinated fish only one } \\
\text { significant increase was seen relative to control fish, of IL-17A/F2a in the gills, whether } \\
\text { the fish were challenged with Y. ruckeri or given the saline placebo. It was also } \\
\text { apparent in gills and head kidney that the level of IL-17A/F1b remained elevated in the } \\
\text { Y. ruckeri challenged fish at a time when it had decreased in saline injected fish. The } \\
\text { relative importance of these isoforms for disease resistance remains to be determined. }\end{array}$ \\
\hline Response to Reviewers: & $\begin{array}{l}\text { Reviewer } 1 \\
\text { "I must repeat the request that they show that in the experiments of Fig. } 7 \text { the } \\
\text { recombinant cytokines did change the expression of marker genes. That is not } \\
\text { negotiable. A simple traditional semi-quatitative RT-PCR analysis (gel electrophoresis } \\
\text { of amplified bands) would be sufficient for this requested analysis of the immune }\end{array}$ \\
\hline
\end{tabular}


marker genes. The readers just should know that the particular cell populations, under the particular conditions, were somehow stimulated by the recombinant cytokines."

We have now added as a new figure (Fig. 7) the data showing the trout recombinant cytokines are active on salmon HK cells, as evidenced by marker gene modulation. 
$8^{\text {th }}$ April 2015

Prof M.F. Flajnik

Editor, Immunogenetics

Dear Martin,

Please find enclosed our re-revised paper on "Identification of the salmonid IL-17A/F1a/b, IL-17A/F2b, IL-17A/F3 and IL-17N genes and analysis of their expression following in vitro stimulation and infection".

We have now added as a new figure (Fig. 7) the data showing the trout recombinant cytokines are active on salmon HK cells, as evidenced by marker gene modulation.

With best wishes,

Chris.

Professor C.J. Secombes DSc, FSB, FRSE

Regius Chair of Natural History 
Reviewer 1

"I must repeat the request that they show that in the experiments of Fig.7 the recombinant cytokines did change the expression of marker genes. That is not negotiable. A simple traditional semi-quatitative RT-PCR analysis (gel electrophoresis of amplified bands) would be sufficient for this requested analysis of the immune marker genes. The readers just should know that the particular cell populations, under the particular conditions, were somehow stimulated by the recombinant cytokines."

We have now added as a new figure (Fig. 7) the data showing the trout recombinant cytokines are active on salmon HK cells, as evidenced by marker gene modulation. 
Identification of the salmonid IL-17A/F1a/b, IL-17A/F2b, IL-17A/F3 and IL-17N genes and analysis of their expression following in vitro stimulation and infection.

Tiehui Wang ${ }^{1}$, Yousheng Jiang ${ }^{1,2}$, Alex Wang ${ }^{1}$, Mansourah Husain ${ }^{1}$, Qiaoqing $\mathrm{Xu}^{1,3}$ and Christopher J. Secombes ${ }^{1 *}$

Running title: Salmonid IL-17A/F genes

${ }^{1}$ Scottish Fish Immunology Research Centre, Institute of Biological and Environmental Sciences, University of Aberdeen, Aberdeen AB24 2TZ, UK

${ }^{2}$ College of Fishery and Life Science, Shanghai Ocean University, Shanghai, 201306, China

${ }^{3}$ School of Animal Science, Yangtze University, Jingzhou, Hubei Province, 434020, China

*Author for correspondence:

Prof. C.J. Secombes (c.secombes@abdn.ac.uk)

Scottish Fish Immunology Research Centre,

Institute of Biological and Environmental Sciences,

University of Aberdeen,

Aberdeen AB24 2TZ, UK.

Tel: 0044-1224-272872

Fax: 0044-1224-272396

Key words: IL-17A/F isoform, IL-17N, expression, Atlantic salmon Salmo salar, rainbow trout Oncorhynchus mykiss 


\begin{abstract}
This study identifies four new IL-17A/F isoforms in salmonids, as well as IL-17N. IL17A/F1 and IL-17A/F2 are each represented by two paralogues, with a predicted pseudogene of $\mathrm{IL}-17 \mathrm{~N}$ also apparent in the salmonid genome. Analysis of the sequences and genes of the known IL-17A/F and IL-17N molecules suggests that IL$17 \mathrm{~N}$ is a member within the IL-17A/F subfamily. Analysis of factors that modulated the expression of these genes showed that PHA and PMA were good inducers of salmon IL-17A/F1a and IL-17A/F2a, with rIL-21 a potent stimulator of IL-17A/F1a and IL-17A/F3. The potential involvement of these isoforms during responses postvaccination and infection was also studied. In unvaccinated control fish, Yersinia ruckeri infection resulted in a marked up-regulation of IL-17A/F1a and IL-17N in spleen and head kidney, and IL-17A/F2a and IL-17A/F3 in spleen. In the vaccinated fish only one significant increase was seen relative to control fish, of IL-17A/F2a in the gills, whether the fish were challenged with Y. ruckeri or given the saline placebo. It was also apparent in gills and head kidney that the level of IL-17A/F1b remained elevated in the $Y$. ruckeri challenged fish at a time when it had decreased in saline injected fish. The relative importance of these isoforms for disease resistance remains to be determined.
\end{abstract}




\section{Introduction}

IL-17 (IL-17A) was discovered in 1993, and is the founding member of the IL-17 family of cytokines that also includes IL-17B, IL-17C, IL-17D, IL-17E (IL-25) and IL-17F. It has highest homology (47\% identity) to IL-17F, and is adjacent to this gene in the mammalian genome (chr 6p12 in humans) (Antonysamy and Numasaki 2003). IL-17 is a proinflammatory cytokine that mediates host defence against extracellular pathogens, and is responsible for eliciting antimicrobial proteins and neutrophil chemoattractants. In mammals $\gamma \delta \mathrm{T}$ cells are the main source of IL-17 in naïve animals (McAleer and Kolls 2014), although IL-17 is also released from innate lymphoid cells (ILC3 cells) at mucosal surfaces (Jones et al. 2012) and even from B cells (León and Lund 2013) in an antigen-independent manner. When the innate responses are not sufficient to clear an infection, then $\mathrm{CD} 4+\mathrm{T}$ cells come into play, with IL-17 released in large quantities from $\mathrm{T}$ helper 17 (Th17) cells to direct responses in an antigen-specific manner (McAleer and Kolls 2014).

The IL-17 family of cytokines is known to be ancient, with members present in invertebrates (Li et al. 2014; Vizzini et al. 2015) as well as vertebrates. Within fish, homologues of IL-17D have been found in the jawless lamprey, where they are produced by VLRA lymphocytes in response to T cell mitogens (Guo et al. 2009), and in the skin upon LPS stimulation (Tsutsui et al. 2007). In cartilaginous fish several IL17 family members are present, although the homology to IL-17A-F is not always clear. For example, two genes related to IL-17A and IL-17F, and two related to IL17B and IL-17D are present in elephant shark, in addition to an IL-17C homologue (Venkatesh et al. 2014). In bony fish genes with relatedness to most of the known IL17 family members occur, although in some cases additional paralogues exist (as with IL-17C) and in one case a novel family member appears to be present (IL-17N) (Korenaga et al. 2010; Wang et al. 2010). The additional paralogues are thought to be the result of additional whole genome duplication (WGD) events that have occurred in ray finned fish species before the divergence of the teleosts (3R fish) (Meyer and Van de Peer 2005) and again in some teleost lineages, as with the salmonids (4R fish) (Macqueen and Johnston 2014). In the case of IL-17A homologues, three genes with homology to IL-17A and IL-17F have been identified in the genomes of zebrafish and 
fugu, and hence have been termed IL-17A/F1-3 (Gunimaladevi et al. 2006; Korenaga et al. 2010; Kono et al. 2011). IL-17A/F1 and IL-17A/F2 are adjacent to each other in the teleost fish genome, with IL-17A/F3 at another locus but with highest homology to IL-17A/F1. Both loci have some degree of gene synteny with the mammalian IL17A/IL-17F locus.

In salmonids only one of the IL-17A/F genes had been discovered before the present study, IL-17A/F2 (Mutoloki et al. 2010; Monte et al. 2013). This molecule has highest constitutive expression levels in mucosal tissues (gills, intestine), and is upregulated in vivo in the kidney in response to pathogen infection and after injection with oil-adjuvanted vaccines. In vitro a number of stimulants, including PAMPs and mitogens, can also up-regulate trout IL-17A/F2 in head kidney primary cultures (Monte et al. 2013). In the only study of fish IL-17A/F bioactivity to date, trout recombinant IL-A/F2 was shown to increase the expression of proinflammatory cytokines (IL-6, IL-8) and the antimicrobial peptide BD-3 (Monte et al. 2013). With the sequencing of the salmon and trout genomes in the last couple of years (Davidson et al. 2010; Berthelot et al. 2014), the time became right to study whether the other isoforms of IL-17A/F exist in salmonids and to ascertain the number of paralogues present. In addition, it is also now possible to determine whether the novel IL-17N is present and if so to see if the salmonid sequence information helps shed light on the origins of this curious IL-17 family member.

\section{Methods}

\section{Identification and cloning of IL-17A/F and IL-17N genes in salmonids}

The Atlantic salmon whole genome shotgun (WGS) sequence was searched (TBLASTN - Altschul et al. 1990) using fish IL-17A/F and IL-17N protein sequences. Candidate WGS contigs (Table 1) were identified and exons predicted as described previously (Wang et al. 2014a; Qi et al. 2015). Primers (Table 1) were designed against the predicted exons and used for 5'- and 3'-RACE using a mixed SMART cDNA as described previously (Wang and Secombes, 2003). The cloning of the PCR products yielded full-length cDNA sequences from five salmon IL-17A/F genes designated as IL-17A/F1a, 1b, 2a, $2 \mathrm{~b}$ and 3, and IL-17N, according to their 
identities to known fish IL-17A/F and IL-17N molecules (Gunimaladevi et al. 2006; product obtained using primers against WGS contig AGKD01056896 was also cloned and sequenced, and found to share high identity (\%) with salmon IL-17N. However, no relevant open reading (ORF) frame was found due to insertions and deletions that cause a shift in the ORF, suggesting it is an IL-17N pseudogene (see results).

IL-17A/F2a has been already been cloned in rainbow trout (Monte et al. 2013). The other trout counterparts of the salmon IL-17A/F and IL-17N genes were amplified from a mixed tissue cDNA sample using primers designed in the 5'- and 3'untranslated regions (UTR) of the salmon sequences (Table 1), then cloned and sequenced. The genomic sequences of trout IL-17A/F isoforms were identified from the recent release of the trout WGS contigs (Berthelot et al. 2014).

In addition, the spotted gar (Lepisosteus oculatus) genome (Amores et al. 2011) was analysed for IL-17A/F and IL-17N genes and the corresponding loci, as a species that has not undergone additional WGD events (ie is a $2 \mathrm{R}$ fish) and is thus a useful outgroup for the sequence analysis.

\section{Sequence analysis}

The DNA and protein sequence analysis was as described previously (Wang et al. 2011a). Briefly, the nucleotide sequences generated were assembled and analysed using the AlignIR programme (LI-COR, Inc.). Gene organisation was predicted at NCBI using the Spidey program (http://www.ncbi.nlm.nih.gov/spidey/). Protein identification was carried out at http://www. expasy.org/tools/ (Gasteiger et al. 2005) and the presence of a signal peptide was predicted using SignalP (version 4.1) (Petersen et al. 2011). Global sequence comparison was performed using MatGAT (Campanella et al. 2003). A multiple sequence alignment was generated using CLUSTALW (version 1.82) (Chenna et al. 2003) and shaded using BOXSHADE (version 3.21, http://www.ch.embnet.org/software/BOX_form.html). A phylogenetic tree of known fish IL-17 molecules was constructed using the neighbour-joining (NJ) method with the pairwise deletion option within the MEGA6.1 programme (Tamura et al. 2013), and was bootstrapped 10,000 times. The synteny of IL-17A/F loci was analysed using 
Genomicus (database version 78.01) (Louis et al. 2013). Finally the local identities between introns were identifies using EMBOSS Matcher program at the European Bioinformatics Institute (http://www.ebi.ac.uk/Tools/psa/emboss_matcher/nucleotide.html).

\section{Comparative gene expression analysis by real-time RT-PCR}

The primers (Table 1) for real-time-PCR were designed so that at least one primer crossed an intron, to ensure that genomic DNA could not be amplified under the PCR conditions used. To directly compare the expression level of the different IL-17A/F isoforms and IL-17N, a reference was constructed using equal molar amounts of PCR product from each gene, including the house keeping gene elongation factor-1 $\alpha$ (EF$1 \alpha)$. The relative expression level of each sample was normalized against the expression level of EF-1 $\alpha$.

\section{Transcript expression of salmonid IL-17A/F and IL-17N isoforms in vivo}

Atlantic salmon were reared in a fresh water aquarium at $12^{\circ} \mathrm{C}$ and fed with commercial pellets (EWOS) twice daily. Six fish (average weight, $34 \mathrm{~g}$ ) were killed by a schedule 1 method and 15 tissues (tail fin, gills, thymus, brain, scales, skin, muscle, liver, spleen, gonad (mixed sex, immature gonad), head kidney, caudal kidney, intestine, heart and blood cells) were collected and processed as described previously (Husain et al. 2012; Xu et al. 2014; Jiang et al. 2015). The RNA preparation, cDNA synthesis and real-time PCR analysis of gene expression was also as described previously (Wang et al. 2011a, b).

\section{Preparation and stimulation of salmon head kidney (HK) cells}

The preparation of salmon HK cells was as described previously (Wang et al. 2011a), with some modifications. The HK was aseptically removed from freshly killed fish and leukocyte suspensions prepared by passing the tissues through a $100 \mu \mathrm{m}$ nylon mesh with incomplete medium: L-15 medium (Invitrogen) plus $100 \mathrm{U} / \mathrm{ml}$ penicillin, $100 \mu \mathrm{g} / \mathrm{ml}$ streptomycin, $0.5 \%$ foetal calf serum (FCS), supplemented with $10 \mathrm{U} / \mathrm{ml}$ heparin. The cells were then centrifuged at $200 \mathrm{~g}$ for $5 \mathrm{~min}$ and washed once using incomplete medium. The cells were re-suspended in complete medium (as for 
incomplete medium but with 10\% FCS) and a viable leukocyte count performed by trypan blue (Invitrogen) exclusion using a haemocytometer. The cells were diluted to 1.5-2 $\times 10^{6}$ leukocytes $/ \mathrm{ml}$ in complete medium and then seeded into 12-well plates (Nunc) ( $2 \mathrm{ml}$ cells/well). The cells were then stimulated with PAMPs (LPS, $25 \mu \mathrm{g} / \mathrm{ml}$; poly I:C, $50 \mu \mathrm{g} / \mathrm{ml}$ ), phorbol 12-myristate 13-acetate (PMA, $0.1 \mu \mathrm{g} / \mathrm{ml}$ ), phytohaemagglutinin (PHA, from red kidney bean Phaseolus vulgaris, $10 \mu \mathrm{g} / \mathrm{ml}$ ), or a variety of recombinant trout cytokines, including rIL-1 $(20 \mathrm{ng} / \mathrm{ml})$ (Hong et al. 2001); rIL-2 (200 ng/ml) (Diaz-Rosales et al. 2009); rIL-6 (200 ng/ml) (Costa et al. 2011); rIL-21 (100 ng/ml) (Wang et al. 2011a); rIFN- $\gamma(20 \mathrm{ng} / \mathrm{ml}$ ) (Wang et al. 2011b) and rTNF- $\alpha(10 \mathrm{ng} / \mathrm{ml})$ (Hong et al. 2013). All the chemicals were from Sigma-Aldrich and the recombinant cytokine proteins were produced in house as described previously. These cytokines have been shown previously to be bioactive for salmon cells at the doses and conditions used (Wang and Husain 2014; Husain et al. 2014), and to have high purity (ie $>95 \%$ for rIL-21, Wang et al 2011). However it is not known if they act as monomers or as higher order structures. The stimulants were diluted in complete medium just before addition to the cells. The concentrations chosen for each stimulant were deemed optimal, and the cytokines used were shown to be active for salmon HK cells in previous studies (Wang and Husain 2014; Husain et al., 2014). The treatments were terminated at $4 \mathrm{~h}, 8 \mathrm{~h}$ and $24 \mathrm{~h}$ after addition of the stimulants and real-time PCR analysis of expression of IL-17A/F, IL-17N and two marker genes for each recombinant cytokine was performed as described above.

\section{Modulation of IL-17A/F and IL-17N isoforms by vaccination and bacterial challenge}

Since IL-17 is a major effector cytokine released from Th17 cells in response to extracellular bacteria, we next studied the expression modulation of the salmonid IL$17 \mathrm{~A} / \mathrm{F}$ and IL-17N molecules in response to infection with/without prior vaccination with Yersinia ruckeri, the causative agent of Enteric RedMouth Disease (ERM), which is responsible for significant economic losses in salmonid aquaculture worldwide (Tobback et al. 2007). It is possible to induce protective immunity in trout to ERM by injection vaccination if performed at appropriate temperatures (Raida et al. 2008). Transmission of $Y$. ruckeri into the host normally occurs by direct contact with infected fish or carriers. It has been suggested that the bacteria first adhere to the gill 
mucus, and then invade the branchial vascular system which facilitates the colonization of internal organs, including the kidney and spleen (Harun et al. 2011).

We took advantage of samples that were already archived from a previous rainbow trout experiment, performed as described by Harun et al. (2011) but with some modifications. Briefly, rainbow trout were kept in recirculating freshwater at $14^{\circ} \mathrm{C}$. The vaccination and challenge experimental procedure was performed under a UK Home Office Project Licence to CJS, approved by a local ethical review committee. A group of 32 trout were vaccinated with the commercial vaccine AquaVac ${ }^{\mathrm{TM}} \mathrm{ERM}$ (Intervet Schering-Plough) by intraperitoneal (ip) injection with 0.1 $\mathrm{ml}$ of vaccine, as recommended by the manufacturer. An additional group of 32 trout were injected ip with $0.1 \mathrm{ml}$ phosphate buffered saline (PBS) to serve as controls. Ten weeks later the fish were challenged by ip injection, with Y. ruckeri strain MT3072 at $0.5 \mathrm{ml} /$ fish $\left(1 \times 10^{6} \mathrm{cfu} / \mathrm{ml}\right)$ or $0.5 \mathrm{ml}$ of PBS as control. The preparation and titration of the bacteria was as described previously (Harun et al. 2011). Naïve fish start to show signs of disease at day 3 under the same challenge dose, which causes $100 \%$ mortality, thus the fish were sampled at day 1 and day 2 to examine IL-17A/F and IL$17 \mathrm{~N}$ isoform expression. Four fish from each group were killed at each sampling point, with gills, HK and spleen collected from each fish, homogenized in TRI reagent (Sigma-Aldrich) and stored at $-80^{\circ} \mathrm{C}$ ready for processing. The average $( \pm \mathrm{SEM})$ weight of the fish at sampling was $211.6( \pm 6.3) \mathrm{g}$.

\section{Statistical analysis}

The measurements of real-time PCR were analyzed using the IBM SPSS Statistics 22 package (SPSS Inc., Chicago, Illinois) as described previously (Wang et al. 2011a,b). The data were expressed initially as arbitrary units after normalization to the expression level of EF-1 $\alpha$, with the lowest expression level in a data set defined as 1 . The data were then $\log 2$ transformed to improve the normality of data distribution. One way-analysis of variance (ANOVA) and the LSD post hoc test were used to analyse the expression data. When data consisted of sets of samples from individual fish, a Paired-Sample T-test was applied. 


\section{Results}

\section{Molecular characterisation of IL-17A/F and IL-17N isoforms in salmonids}

By analysis of Atlantic salmon WGS sequences, five IL-17A/F loci and two IL-17N loci have been identified. Six full-length cDNA sequences were obtained by cloning, in addition to a possible IL-17N pseudogene (Supplementary figure (Fig. S) 1-7, and Table 2). The cDNA sequence of each salmon IL-17A/F isoform (IL-17A/F1a, 1b, 2a, 2b, 3) and IL-17N, contains a 5'-UTR, a main ORF, and a 3'-UTR with 2-4 ATTTA motifs (Khabar 2010), a polyadenylation signal and a poly A tail (Figs. S1S6). There are five ATG (s) upstream of the main ORF in salmon IL-17A/F1b and one in IL-17A/F2b, that may have a regulatory role at the translational level (Kochetov et al. 2008). Four additional IL-17A/F cDNAs for IL-17A/F1a, 1b, 2b, 3 and IL-17N were also cloned in rainbow trout using primers designed against the relevant salmon sequence (Figs. S8-12). Each trout sequence contains an ORF and has a predicted signal peptide. WGS contigs to each of the trout genes can be identified in the recent release of the trout genome, which covered the full-length cDNA sequence except WGS contig CCAF010087661 that contained only the last exon of the trout IL-17A/F1b gene (Table 3).

Human IL-17A and IL-17F genes have a 3 (coding) exon/2 intron structure with the first intron phase 0 and the second intron phase II. This is also seen in the known fish IL-17A/F and IL-17N genes, with the exception of the fugu IL-17A/F3 gene, which has an additional phase II intron (Fig. 1). Two IL-17A/F genes were also discovered by us in the spotted gar (L. oculatus) and had this same general structure (3 exons/2 introns). The salmonid IL-17A/F1a, 1b, 2a, 2b and IL-17N share a similar gene organisation but in several cases there was one extra exon present in the 5'-UTR, as seen with salmon IL-17A/F1b and salmon/trout IL-17A/F2b (Fig. 1). However, also in the case of the salmonid IL-17A/F3 genes the gene organisation was divergent, with four coding exons in rainbow trout (as in fugu) or five coding exons in Atlantic salmon, respectively (Fig. 1). Interestingly, the first $155 \mathrm{bp}$ sequence of the last exon of salmon IL-17A/F3 is missing in the trout IL-17A/F3 cDNA and genomic DNA and encodes a peptide sequence (33 aa) without any identities to other IL-17A/F molecules (Fig. S5). Lastly, it is noteworthy that the IL-17A/F isoforms of the 3R fish 
(including the 4R salmonids) can be divided into two groups according to the size of the coding exon 2. This exon in IL-17A/F1 and IL-17A/F3 genes is larger (191-242 bp) than that of IL-17A/F2 and IL-17N genes (164-176 bp, Fig. 1), with exon 2 of the 2R spotted gar IL-17A/F and human IL-17A/ IL-17F genes being somewhat between these two (197-221 bp). When examining the gene organisation of IL-17C and IL17D it is apparent that they differ from the IL-17A/F genes described above in terms of the coding exon sizes (Fig. 1). The IL-17D genes from salmonids and other fish species (eg zebrafish and fugu, data not shown) have a two exon/one intron structure, but that from human and other mammals (eg mouse) have an extra intron in the 5'UTR.

All of the salmonid IL-17A/F proteins have a predicted signal peptide and mature peptide as in other vertebrate IL-17 molecules. Also, similar to the grouping by exon 2, the mature peptide encoded by the salmonid IL-17A/F1 and IL-17A/F3 genes is larger (140-172 aa/15.86-19.29 kDa) than that of IL-17A/F2 and IL-17N (118-121 aa/13.18-13.94 kDa) (Tables 2 and 3). The mature peptides of salmonid IL17A/F1a, 1b, 2a, 2b and 3 are basic with a pI of 8.25-10.10 and contain 1-2 potential $\mathrm{N}$-glycosylation sites. However, salmonid IL-17N mature peptides are acidic with a pI of 5.64-6.13 and have no N-glycosylation sites. The amino acid identity/similarity between salmonid IL-17A/F orthologues is relatively high (84.9-93.5\% identity/ 90.695.9\% similarity) with the exception of salmonid IL-17A/F3 that drops to $75.4 \%$ identity due to the insertion in the last exon of salmon IL-17A/F3 (Table S1). It is noteworthy that salmonid IL-17A/F2 molecules generally have higher similarities to salmonid IL-17N (41.5-46.9\%) than to salmonid IL-17A/F1 (37.7-43.3\%) and IL17A/F3 (32.6-41.3\%) (Table S1).

Structurally, mammalian IL-17A and IL-17F can form homo- and heterodimers. Each monomer is composed of two pairs of antiparallel $\beta$-sheets (strands 1-4), with the second and fourth strands connected by two disulphide bonds in a manner homologous to that of the cysteine-knot family proteins (Hymowitz et al. 2001; Ely et al. 2009). A multiple alignment of the mature peptide from known fish (incl. gar and salmonids) and mammalian IL-17A and IL-17F revealed a general structural conservation. The four $\beta$-strands, and the four cysteine residues connecting $\beta$-strands 2 and 4 are well conserved (Fig. 2). Two additional cysteine residues, one at 
the $\mathrm{N}$-terminal and the other between $\beta$-strands 3 and 4 , are also conserved in $3 \mathrm{R}$ fish IL-17A/F2, IL-17N, the two IL-17A/F from 2R spotted gar and the IL-17A/IL-17F molecules in mammals. In contrast a potential $\mathrm{N}$-glycosylation site close to the $\beta$ strand 1 is conserved in most of the $3 \mathrm{R}$ fish IL-17A/F1 and IL17A/F3, one of the gar IL-17A/F molecules and in IL-17A (Fig. 2). One additional N-glycosylation site is also conserved in $3 \mathrm{R}$ fish $\mathrm{IL}-17 \mathrm{~A} / \mathrm{F} 1$. Interestingly, there is basic $\mathrm{K} / \mathrm{R}$ rich region lying between $\beta$-strands 3 and 4 in all IL-17A/F3 molecules.

\section{Evolutionary analysis of fish IL-17A/F and IL-17N molecules}

To help clarify the relationship of the fish IL-17 molecules now that the full repertoire of the salmonid and gar IL-17A/F molecules have been found, an unrooted phylogenetic tree of known fish IL-17 sequences was constructed (Fig. 3), based on the multiple alignment in Fig. S13. The groupings of 3R fish IL-17A/F1, IL-17A/F2, IL-17A/F3, IL-17N, IL-17C and IL-17D were all well supported as expected (Wang et al. 2014b, Secombes et al. 2011). It was also clear that IL-17A/F1 and IL-17A/F3 were closely related, with one of the gar IL-17A/F branching at the base of this clade. Most interesting was the strong support linking the IL-17A/F molecules and the IL$17 \mathrm{~N}$ genes (94\%), and whilst the second gar IL-17A/F branched with the (3R fish) IL$17 \mathrm{~A} / \mathrm{F} 2$ molecules, there was a grouping that consisted of the IL-17A/F2 and IL-17N.

To further clarify the evolutionary relationship of the fish IL-17A/F genes, synteny analysis was performed using the Genomicus program (Louis et al. 2013). The tetrapod (human and chicken) IL-17A and IL-17F genes are aligned head to head and linked to the MCM3 and PAQR8 genes that are also linked to fish IL-17A/F genes in spotted gar, tilapia and zebrafish (Fig. 4), suggesting a common origin of these genes. However, the transcriptional direction of IL-17A/F1 and IL-17A/F2 are in the opposite orientation (tail to tail) in both $2 \mathrm{R}$ and $3 \mathrm{R}$ fish, indicating that a local gene duplication of IL-17A/F genes may have happened independently in fish and in tetrapods. Furthermore, the IL-17A/F1 and IL-17A/F2 locus (with linked genes EMILIN1, GPN1, STMN4, MCM3, PAQR8, ZNF395b and PNOCB) in the 2R spotted gar is well conserved as two loci in different chromosomes in the 3R fish (eg tilapia and zebrafish). The 3R fish IL-17A/F1 and IL-17A/F3 genes share a conserved transcriptional direction with the 2R gar IL-17A/F1 gene (Fig. 4) and group together 
in the phylogenetic tree (Fig. 3), suggesting that they are paralogues of $2 \mathrm{R}$ fish IL17A/F1. No synteny could be identified in the fish IL-17N loci with other IL-17 loci as reported by Kono et al. (2011).

The incompleteness of the genome sequence prevents synteny analysis of the IL$17 \mathrm{~A} / \mathrm{F}$ genes in salmonids. To shed light on the origin of salmonid IL-17A/F paralogues, the identities of intron sequences were analysed using the EMBOSS Matcher program that identifies local similarities (Table S2). Both intron 1 and intron 2 in the coding region share highest identities (81-94.5\%) between salmonid IL-17A/F orthologues, eg IL-17A/F1a from salmon and trout. They also share high identities (68.9-81.6\%) between paralogues of salmonid IL-17A/F genes, eg IL-17A/F2a and IL-17A/F2b from salmon, trout or to each other. The local intron identities between paralogues are apparently higher than between different subfamily members, eg, 77.8$81.6 \%$ between IL-17A/F1 paralogues, but only 54.8-67.8\% between IL-17A/F1 and other subfamily members (Table S2). These data suggest that the paralogues of IL17A/F1 and IL-17A/F2 indeed arose from the salmonid WGD.

\section{Tissue expression patterns of IL-17A/F and IL-17N isoforms in Atlantic salmon}

Comparative examination of the expression of IL-17A/F isoforms in Atlantic salmon tissues from six healthy fish was next performed. Differences were seen between the different isoforms and in some cases the two IL-17A/F1 and IL-17A/F2 paralogues (Fig. 5). For example IL-17A/F1a was more highly expressed in heart, intestine and thymus relative to IL-17A/F1b, but the latter was more highly expressed in liver, scales, brain and caudal kidney. With the IL-17A/F2 paralogues, IL-17A/F2a was more highly expressed in heart, liver, intestine, skin, gills, thymus, tail fin and caudal kidney, with IL-17A/F2b only significantly higher in head kidney. IL-17A/F3 was most highly expressed in caudal kidney, spleen, brain, gills, intestine and thymus. Lastly, IL-17N was most highly expressed in brain, followed by gonad, spleen, blood cells, head kidney and thymus. Of the different isoforms, IL-17A/F2a had the highest expression level in gills, followed by IL-17N in brain and IL-17A/F1b in scales, brain and caudal kidney. 


\section{Modulation of expression of Atlantic salmon IL-17A/F isoforms and IL-17N in vitro}

The HK is a major lymphoid tissue in fish and contains many types of immune cells including T cell, B cells, macrophages and others. Hence HK cells were used to investigate the potential modulation of $\mathrm{IL}-17 \mathrm{~A} / \mathrm{F}$ and $\mathrm{IL}-17 \mathrm{~N}$ gene expression by a variety of immune stimulants, including PAMPs, mitogens and cytokines. The expression of salmon IL-17A/F isoforms and IL-17N was refractory to stimulation with LPS and poly I:C at $4 \mathrm{~h}$ and $8 \mathrm{~h}$ (Fig. 6). However, at $24 \mathrm{~h}, \mathrm{IL}-17 \mathrm{~A} / \mathrm{F} 3$ expression was slightly decreased ( 0.6 fold) in LPS stimulated samples and increased after poly I:C stimulation (4.0 fold), whilst IL-17A/F1b was slightly decreased by poly I:C. PHA up-regulated the expression of IL-17A/F1a and IL-17A/F2a from $4 \mathrm{~h}$, which peaked at $8 \mathrm{~h}$ with a 12 -fold and 82 -fold increase respectively, with the effects lost at $24 \mathrm{~h}$. PMA strongly upregulated the expression of IL-17A/F1a (121-fold at $8 \mathrm{~h}$ ) and IL-17A/F2a (18 fold at $8 \mathrm{~h}$ ) from $4 \mathrm{~h}$ to $8 \mathrm{~h}$, and IL-17A/F2b and IL-17A/F3 at 8 $\mathrm{h}$, with the effect waning by $24 \mathrm{~h}$. Indeed, PMA treatment significantly decreased IL$17 \mathrm{~A} / \mathrm{F} 1 \mathrm{~b}, \mathrm{IL}-17 \mathrm{~A} / \mathrm{F} 3$ and IL-17N at $24 \mathrm{~h}$ and induced an early decrease of IL17A/F2b expression at 4 h (Fig. 6).

Recombinant cytokines that might potentially affect the expression of IL-17A/F and IL-17N genes were also tested in salmon HK cells. Six trout recombinant cytokines, IL-1 $\beta$, IL-6, TNF- $\alpha$, IFN- $\gamma$, IL-2 and IL-21, have been shown to be active in salmon HK cells by assessing the up-regulation of marker gene expression for each cytokine, ie IL-1 $\beta 1$ and TNF- $\alpha 1$ for IL-1 $\beta$, cathelicidin (CATH) 2 and IL-6 for IL-6, TNF- $\alpha 1$ and CATH1 for TNF- $\alpha 3$; $\gamma$ IP and IL-12 p35a1 subunit for IFN- $\gamma$, and $\gamma$ IP and IFN- $\gamma$ for IL-2 and IL-21 (Fig. 7). In terms of their effects on IL-17A/F and IL-17N expression, in general no effects were seen at $4 \mathrm{~h}$ post-stimulation with the exception of a small increase of IL-17A/F1b expression by IL-2 (2-fold) and IL-21 (2-fold), and IL-17A/F3 by IL-21 (5-fold) (Fig. 8). IL-1 $\beta$ decreased the expression of IL-17A/F1b at $8 \mathrm{~h}$ and $24 \mathrm{~h}$, but had no effects on the other genes at these times. IL-6 had a small stimulatory effect on IL-17A/F3 expression at $24 \mathrm{~h}$ (2-fold). IFN- $\gamma$ decreased the expression of IL-17A/F3 at $8 \mathrm{~h}$, and IL-17N at $24 \mathrm{~h}$. TNF- $\alpha$ weakly increased IL17A/F1a expression at $8 \mathrm{~h}$ (2-fold) but decreased IL-17N expression at $24 \mathrm{~h}$. IL-2 increased IL-17A/F2b expression at $8 \mathrm{~h}$ (3-fold), but decreased IL-17A/F2a 
expression at $24 \mathrm{~h}$. Lastly, IL-21 was a potent inducer of IL-17A/F1a (increased up to 12-fold), and IL-17A/F3 (increased up to 8-fold) but had no effect on the expression of IL-17A/F2a/b and IL-17N (Fig. 8).

\section{Modulation of expression of rainbow trout IL-17A/F isoforms and IL-17N in vivo by vaccination and bacterial challenge}

The expression of IL-17A/F isoforms and IL-17N was investigated in gills, spleen and HK of control and vaccinated fish injected with $Y$. ruckeri or PBS as control. The relative expression of IL-17A/F genes in tissues of PBS injected control fish is shown in Fig. S14. For simplicity, the expression levels were expressed as arbitrary units where one unit in each tissue equals the average expression level in the PBS injected control group at day 1 (Fig. 9). In unvaccinated control fish, Y. ruckeri infection resulted in an up-regulated expression in the spleen of IL-17A/F1a (18-fold at day 1 and 148-fold at day 2), IL-17A/F2a (8-fold at day 2), IL-17A/F3 (6-fold at day 2) and IL-17N (4-fold at day 1 and 8-fold at day 2). It also increased the expression of IL17A/F1a (32-fold at day 1 and 33-fold at day 2) and IL-17N (5-fold at day 2) in the HK (Fig. 9). In vaccinated fish, Y. ruckeri challenge did not alter the expression of IL$17 \mathrm{~A} / \mathrm{F} 1 \mathrm{a}, 2 \mathrm{a}, 2 \mathrm{~b}$ and 3 , and IL-17N in any of the three tissues examined, suggesting that an inflammatory immune response had not been initiated in vaccinated fish. Interestingly, the expression of IL-17A/F1b was maintained at a higher level in gills (4-fold) and HK (4-fold) in vaccinated fish 2 days after challenge when the expression level had dropped significantly in vaccinated fish injected with PBS (Fig. 9B). It is also noteworthy that the vaccinated fish expressed a higher level of IL-17A/F2a in the gills at day 2, compared to the control fish (Fig. 9C).

\section{Discussion}

It is clear that salmonids, as with other teleost fish groups, possess multiple IL-17A/F isoforms, with $\mathrm{IL}-17 \mathrm{~A} / \mathrm{F} 1$ and $\mathrm{IL}-17 \mathrm{~A} / \mathrm{F} 2$ apparently the result of a tandem duplication event. This duplication possibly occurred early in bony fish evolution as two genes are also present in the equivalent locus in the holostean gar from our analysis of the IL-17A/F locus following the release of the gar genome (Amores et al. 2011). Interestingly this is a region that shows gene synteny with tetrapod IL-17A/IL- 
17F loci and both the teleost fish IL-17A/F1/IL-17A/F2 and IL-17A/F3 loci. With the locus was duplicated giving rise to a second locus that potentially contained IL17A/F3 and an IL-17A/F4. The existing IL-17A/F3 gene has high homology with IL$17 \mathrm{~A} / \mathrm{F} 1$, as seen in other fish species and now also in salmonids. With the new sequences from this study it is becoming clearer that the novel IL-17 molecule (IL$17 \mathrm{~N}$ ) discovered in fugu (Korenaga et al. 2010) may be this missing IL-17A/F4 molecule, since it has relatively similar gene organisation, high homology to IL$17 \mathrm{~A} / \mathrm{F} 2$, and several conserved features of the protein that in encodes. Whilst the phylogenetic tree analysis is not conclusive, nevertheless it strongly implies that IL$17 \mathrm{~N}$ does indeed belong to the IL-17A/F subfamily. In salmonids a $4^{\text {th }}$ WGD event has occurred, such that multiple paralogues of the IL-17A/F molecules may be present, as seen with the salmonid IL-17A/F1 and IL-17A/F2 genes. A second paralogue of IL-17N was also found, but due to insertions and deletions that cause a shift in the ORF, it is a likely pseudogene. No other IL-17A/F3 genes were found and the expected second paralogue appears to have been lost during salmonid evolution.

Analysis of the gene organisation revealed that IL-17A/F3 was unusual in having four or five exons. In the fugu and trout genes the last two exons may result from an intron insertion (phase II) into the last exon of the IL-17A/F3 gene in other fish species. Hence this insertion potentially happened after the divergence of the ostariophysi from the main teleost lineage. A further intron insertion (phase 0) appears to have happened in the last exon, after the divergence of Atlantic salmon from rainbow trout, giving a unique five exon/four intron structure to the salmon gene. Interestingly, the first $155 \mathrm{bp}$ sequence of the last exon of salmon IL-17A/F3 is missing in the trout IL-17A/F3 cDNA and genomic DNA, but is present in the genomes of rainbow trout and Atlantic salmon as hundreds of copies, suggesting there was a species-specific insertion of a transposable element. IL-17A/F3 is also the only isoform in which there is basic K/R rich region lying between $\beta$-strands 3 and 4 , that may function as a nuclear localisation signal (Marfori et al. 2013).

Differences in the expression profile of the different IL-17A/F isoforms and IL-17N have been noted previously in zebrafish and fugu (Gunimaladevi et al. 2006; Korenaga et al. 2010), although some differences between species are also apparent. 
In the case of IL-17A/F1 it is highly expressed in the intestine in zebrafish and turbot (Costa et al. 2012), with relatively low expression levels elsewhere. IL-17A/F2 has a wider tissue distribution in zebrafish and trout (IL-17A/F2a - Monte et al. 2013), with skin having the highest expression level in fugu. IL-17A/F3 is highly expressed in gills and intestine in zebrafish, or gills and spleen in fugu. Lastly, IL-17N has been shown to be highly expressed in the head kidney of fugu. The comparative expression results for the salmon genes presented here also show that differences exist between the isoforms, but that this is complicated by the presence of the pairs of paralogues in the case of IL-17A/F1 and IL-17A/F2. In general the immune tissues and mucosal sites have a relatively high expression level, with tissues such as heart, liver and muscle being relatively low. Curiously the brain has a high expression level of most of these genes, suggesting a role in the nervous system.

Perhaps more importantly is the modulation of expression of these genes seen following stimulation. Most previous studies have been quite limited in terms of the stimulants used or the isoforms compared. For example, in fugu LPS stimulation of head kidney cells was shown to increase IL-17A/F3 and IL-17N expression in a comparative study of IL-17 isoforms (Korenaga et al. 2010). In turbot, studies of IL17A/F1 have shown that in vivo exposure to Aeromonas salmonicida or in vitro stimulation of cells with PMA increases IL-17A/F1 expression (Costa et al. 2012), whilst in trout our previous studies on IL-17A/F2a have shown in vivo infection (bacteria, virus and parasite) or in vitro stimulation with PMA, calcium ionophore and PHA are all good inducers (Monte et al. 2013). IL-17A/F2 is also increased in head kidney of carp infected with Trypanoplasma carassii (but not T. borreli) (Ribeiro et al. 2010). In the best comparative study to date (Zhang et al. 2014), it has been shown that bath vaccination (with attenuated Vibrio anguillarum) of zebrafish induces all three IL-17A/F isoforms at mucosal sites (gills, gut, skin), with the exception of IL17A/F3 in gills, with a particularly marked increase of IL-17A/F2 in gut. In contrast injection vaccination increased all three isoforms in skin but only IL-17A/F2 in gills and none in gut. Following bath challenge of the vaccinated fish 28 days later, all three isoforms were again induced at these sites (except IL-17A/F3 in gills) in bath vaccinated fish. In injection vaccinated fish the challenge induced higher responses in the gills, lower responses in the skin and none in the gut. 
In the present study we show that PHA and PMA are good inducers of IL17A/F2a in salmon (head kidney cells), as seen previously in trout, and also highly upregulate IL-17A/F1a and to some degree IL-17A/F2b and IL-17A/F3. Curiously they do not affect IL-17A/F1b and IL-17N expression. We also see no induction by poly I:C with the exception of IL-17A/F3 (in agreement with our previous study of IL-17A/F2a), despite the fact that viral infection induced IL-17A/F2a expression in trout (Monte et al. 2013). Of the cytokines tested, it was clear the rIL-21 was the most potent stimulator, for IL-17A/F1a and IL-17A/F3 but not the other isoforms. The other cytokines had relatively small effects with no clear trends. Upon bacterial infection (of trout) there was a large response seen on IL-17A/F1a and IL-17N expression in the spleen at days 1 and 2, with a similar effect in the kidney with IL17A/F1a and at day 2 in the spleen for L-17A/F2a. We had previously also seen a later (day 2) induction in the kidney for IL-17A/F2a that was not apparent this time. Curiously in the vaccinated fish only one significant increase was seen relative to control fish, of IL-17A/F2a in the gills at day 2, whether the fish were challenged with Y. ruckeri or given the saline placebo. Also it was apparent that in the gills and head kidney of saline injected vaccinated fish the level of IL-17A/F1b had decreased by day 2, whilst in the $Y$. ruckeri challenged fish no decrease was seen. It is not clear how these findings relate to disease resistance in these fish, but conversely it would seem that high levels of IL-17A/F1a and IL-17N in the spleen and/or head kidney (at these timings) are not protective.

In conclusion, we have identified four additional IL-17A/F isoforms in salmonids, as well as IL-17N. IL-17A/F1 and 2 exist as two paralogues, with a predicted pseudogene of IL-17N apparent in the salmonid genome that was likely the second paralogue of this molecule. Our sequence analysis with these new genes strongly suggest that IL-17N is an IL-17A/F and likely a gene related to IL-17A/F2, with the IL-17A/F locus likely duplicated by the $3^{\text {rd }}$ WGD event at the base of the teleosts and with IL-17N subsequently moving elsewhere in the genome. The relative importance of these isoforms for disease resistance remains to be determined, complicated by the differing expression patterns seen upon stimulation and infection.

\section{Acknowledgments}


TW received funding from the MASTS pooling initiative (The Marine Alliance for

Science and Technology for Scotland) funded by the Scottish Funding Council (grant reference HR09011) and contributing institutions. MH was funded by the Public Authority of Applied Education and Training (KUWAIT). YJ and QX were supported financially by the National Scholarship Council of China. This work was partially supported financially by the European Commission, contract Nos. 222719 (LIFECYCLE) and 311993 (TargetFish).

\section{References}

Altschul SF, Gish W, Miller W, Myers EW, Lipman DJ (1990) Basic Local Alignment Search Tool. J Mol Biol 215:403-410.

Amores A, Catchen J, Ferrara A, Fontenot Q, Postlethwait JH (2011) Genome evolution and meiotic maps by massively parallel DNA sequencing: spotted gar, an outgroup for the teleost genome duplication. Genetics 188:799-808.

Antonysamy MA, Numasaki M (2003) Interleukin-17 (IL-17, IL-25). In: Thomson AW, Lotze MT (eds) The Cytokine Handbook, $4^{\text {th }}$ Edition. Academic Press, pp. 475502.

Berthelot C, Brunet F, Chalopin D, Juanchich A, Bernard M, Noel B, Bento P, Da Silva C, Labadie K, Alberti A, Aury JM, Louis A, Dehais P, Bardou P, Montfort J, Klopp C, Cabau C, Gaspin C, Thorgaard GH, Boussaha M, Quillet E, Guyomard R, Galiana D, Bobe J, Volff JN, Genet C, Wincker P, Jaillon O, Crollius HR, Guiguen Y (2014) The rainbow trout genome provides novel insights into evolution after wholegenome duplication in vertebrates. Nature Communications 5:3657.

Campanella JJ, Bitincka L, Smalley J (2003) MatGAT: An application that generates similarity/identity matrices using protein or DNA sequences. BMC Bioinformatics $4: 29$. 
Chenna R, Sugawara H, Koike T, Lopez R, Gibson TJ, Higgins DG, et al. (2003) Multiple sequence alignment with the clustal series of programs. Nucleic Acids Res 31:3497-3500.

Costa MM, Maehr T, Diaz-Rosales P, Secombes CJ, Wang T (2011) Bioactivity studies of rainbow trout (Oncorhynchus mykiss) interleukin-6: effects on macrophage growth and antimicrobial peptide gene expression. Mol Immunol 48:1903-1916.

Costa MM, Pereiro P, Wang T, Secombes CJ, Figueras A, Novoa B (2012) Characterization and gene expression analysis of the two main Th17 cytokines (IL17A/F and IL-22) in turbot, Scophthalmus maximus. Dev Comp Immunol 38:505-516.

Davidson, WS, Koop BF, Jones SJM, Iturra P, Vidal R, Maass A, Jonassen I, Lien S, Omholt SW (2010) Sequencing the genome of the Atlantic salmon (Salmo salar). Genome Biology 11:403.

Díaz-Rosales P, Bird S, Wang TH, Fujiki K, Davidson WS, Zou J, Secombes CJ (2009) Rainbow trout interleukin-2: cloning, expression and bioactivity analysis. Fish Shellfish Immunol 27:414-422.

Ely LK, Fischer S, Garcia KC (2009) Structural basis of receptor sharing by interleukin 17 cytokines. Nature Immunol 10:1245-1251.

Gasteiger E, Hoogland C, Gattiker A, Duvaud S, Wilkins M R, Appel RD, Bairoch A (2005) Protein Identification and Analysis Tools on the ExPASy Server. In: Walker JM (ed) The Proteomics Protocols Handbook. Humana Press, pp. 571-607.

Gunimaladevi I, Savan R, Sakai M (2006) Identification, cloning and characterization of interleukin-17 and its family from zebrafish. Fish Shellfish Immunol 21:393-403.

Guo P, Hirano M, Herrin BR, Li J, Yu C, Sadlonova A, Cooper MD (2009) Dual nature of the adaptive immune system in lampreys. Nature 459:796-801. 
Harun NO, Wang T, Secombes CJ (2011) Gene expression profiling in naïve and vaccinated rainbow trout after Yersinia ruckeri infection: insights into the mechanisms of protection seen in vaccinated fish. Vaccine 29:4388-99.

Hong S, Li R, Xu Q, Secombes CJ, Wang T (2013) Two types of TNF- $\alpha$ exist in teleost fish: Phylogenetic, expressional and bioactivity analysis of Type II TNF-a3 in rainbow trout Oncorhynchus mykiss. J Immunol 191:5959-5972.

Hong S, Zou J, Crampe M, Peddie S, Scapigliati G, Bols N, Cunningham C, Secombes CJ (2001) The production and bioactivity of rainbow trout (Oncorhynchus mykiss) recombinant IL-1 $\beta$. Vet Immunol Immunopathol 81:1-14.

Husain M, Bird S, van Zwieten R, Secombes CJ, Wang T (2012) Cloning of the IL-

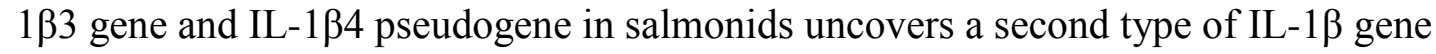
in teleost fish. Dev Comp Immunol 38:431-446.

Husain M, Martin SA, Wang T (2014) Identification and characterisation of the IL-27 p28 subunits in fish: Cloning and comparative expression analysis of two p28 paralogues in Atlantic salmon Salmo salar. Fish Shellfish Immunol. 41:102-112.

Hymowitz SG, Filvaroff EH, Yin JP, Lee J, Cai L, Risser P, Maruoka M, Mao W, Foster J, Kelley RF, Pan G, Gurney AL, de Vos AM, Starovasnik MA (2001) IL-17s adopt a cystine knot fold: structure and activity of a novel cytokine, IL-17F, and implications for receptor binding. EMBO J 20:5332-5341.

Jiang Y, Husain M, Qi Z, Wang T (2015) Identification and expression analysis of two interleukin-23a (p19) isoforms, in rainbow trout Oncorhynchus mykiss and Atlantic salmon Salmo salar. Mol Immunol 66:216-228.

Jones SA, Sutton CE, Cua D, Mills KHG (2012) Therapeutic potential of targeting IL17. Nature Immunology 13:1022-1025.

Khabar KS (2010) Post-transcriptional control during chronic inflammation and cancer: a focus on AU-rich elements. Cell Mol Life Sci 67:2937-2955. 
Kochetov AV, Ahmad S, Ivanisenko V, Volkova OA, Kolchanov NA, Sarai A (2008) uORFs, reinitiation and alternative translation start sites in human mRNAs. FEBS Lett 582:1293-1297.

Kono T, Korenaga H, Sakai M (2011) Genomics of fish IL-17 ligand and receptors: a review. Fish Shellfish Immunol 31:635-643.

Kumari J, Larsen AN, Bogwald J, Dalmo RA (2009) Interleukin-17D in Atlantic salmon (Salmo salar): molecular characterization, 3D modelling and promoter analysis. Fish Shellfish Immunol. 27: 647-59.

Korenaga H, Kono T, Sakai M (2010) Isolation of seven IL-17 family genes from the Japanese pufferfish Takifugu rubripes. Fish Shellfish Immunol 28:809-818.

León B, Lund FE (2013) IL-17-producing B cells combat parasites. Nature Immunol $14: 419-421$.

Li J, Zhang Y, Zhang Y, Xiang Z, Tong Y, Qu F, Yu Z (2014) Genomic characterization and expression analysis of five novel IL-17 genes in the Pacific oyster, Crassostrea gigas. Fish Shellfish Immunol 40:455-465.

Louis A, Muffato M, Roest Crollius H (2013) Genomicus: five genome browsers for comparative genomics in eukaryota. Nucleic Acids Res. 41(Database issue): D700705.

Macqueen DJ, Johnston IA (2014) A well-constrained estimate for the timing of the salmonid whole genome duplication reveals major decoupling from species diversification. Proc Roy Soc B 281:20132881.

Marfori M, Mynott A, Ellis JJ, Mehdi AM, Saunders NF, Curmi PM, Forwood JK,Bodén M, Kobe B (2011) Molecular basis for specificity of nuclear import and prediction of nuclear localization. Biochim Biophys Acta 1813:1562-1577. 
McAleer JP, Kolls JK (2014) Directing traffic: IL-17 and IL-22 coordinate pulmonary immune defense. Imm Rev 260:129-144.

Meyer A, Van de Peer Y (2005) From 2R to 3R: evidence for a fish-specific genome duplication (FSGD). Bioessays 27:937-945.

Monte MM, Wang T, Holland JW, Zou J, Secombes CJ (2013) Cloning and characterization of rainbow trout interleukin-17A/F2 (IL-17A/F2) and IL-17 receptor A: expression during infection and bioactivity of recombinant IL-17A/F2. Infect Immun 81:340-353.

Mutoloki S, Cooper GA, Marjara IS, Koop BF, Evensen Ø (2010) High gene expression of inflammatory markers and IL-17A correlates with severity of injection site reactions of Atlantic salmon vaccinated with oil-adjuvanted vaccines. BMC Genomics 11:336.

Petersen TN, Brunak S, von Heijne G, Nielsen H (2011) SignalP 4.0: discriminating signal peptides from transmembrane regions. Nature Methods 8:785-786.

Qi Z, Jiang Y, Holland JW, Nie P, Secombes CJ, Wang T. (2015) Identification and expression analysis of an atypical chemokine receptor-2 (ACKR2)/CC chemokine binding protein-2 (CCBP2) in rainbow trout (Oncorhynchus mykiss). Fish Shellfish Immunol 44:389-398.

Raida MK, Buchmann K (2008) Bath vaccination of rainbow trout (Oncorhynchus mykiss Walbaum) against Yersinia ruckeri: effects of temperature on protection and gene expression. Vaccine 26:1050-1062.

Ribeiro CMS, Pontes MJSL, Bird S, Chadzinska M, Scheer M, Verburg-van Kemenade BML, Savelkoul HFJ, Wiegertjes GF (2010) Trypanosomiasis-induced Th17-like immune responses in carp. PLOS ONE 5:e13012.

Tamura K, Stecher G, Peterson D, Filipski A, Kumar S (2013) MEGA6: Molecular Evolutionary Genetics Analysis version 6.0. Mol Biol Evol 30:2725-2729. 
Tobback E, Decostere A, Hermans K, Haesebrouck F, Chiers K (2007) Yersinia ruckeri infections in salmonid fish. J Fish Dis 30:257-268.

Tsutsui S, Nakamura O, Watanabe T (2007) Lamprey (Lethenteron japonicum) IL-17 upregulated by LPS-stimulation in the skin cells. Immunogenetics 59:873-882.

Venkatesh B., et al. (2014) Elephant shark genome provides unique insights into gnathostome evolution. Nature 505:174-179.

Vizzini A, Di Falco F, Parrinello D, Sanfratello MA, Mazzarella C, Parrinello N, Cammarata M (2015) Ciona intestinalis interleukin 17-like genes expression is upregulated by LPS challenge. Dev Comp Immunol 48:129-137.

Wang T, Diaz-Rosales P, Costa MM, Campbell S, Snow M, Collet B, Martin SA, Secombes CJ (2011a) Functional characterization of a nonmammalian IL-21: rainbow trout Oncorhynchus mykiss IL-21 upregulates the expression of the Th cell signature cytokines IFN-gamma, IL-10, and IL-22. J Immunol 186:708-821.

Wang T, Huang W, Costa MM, Martin SA, Secombes CJ (2011b) Two copies of the genes encoding the subunits of putative interleukin (IL)-4/IL-13 receptors, IL-4R $\alpha$, IL-13R $\alpha 1$ and IL-13R $\alpha 2$, have been identified in rainbow trout (Oncorhynchus mykiss) and have complex patterns of expression and modulation. Immunogenetics 63:235-253.

Wang T, Husain M (2014) The expanding repertoire of the IL-12 cytokine family in teleost fish: Identification of three paralogues each of the p35 and p40 genes in salmonids, and comparative analysis of their expression and modulation in Atlantic salmon Salmo salar. Dev Comp Immunol 46:194-207.

Wang T, Husain M, Hong S, Holland JW (2014a) Differential expression, modulation, and bioactivity of distinct fish IL-12 isoforms: Implication towards the evolution of Th1-like immune responses. Eur J Immunol 44:1541-1551. 
Wang T, Martin SA, Secombes CJ (2010) Two interleukin-17C-like genes exist in rainbow trout Oncorhynchus mykiss that are differentially expressed and modulated. Dev Comp Immunol 34:491-500.

Wang T, Secombes CJ (2003) Complete sequencing and expression of three complement components, $\mathrm{C} 1 \mathrm{r}, \mathrm{C} 4$ and $\mathrm{C} 1$ inhibitor, of the cla4ssical activation pathway of the complement system in rainbow trout Oncorhynchus mykiss. Immunogenetics 55:615-628.

Wang X, Li C, Thongda W, Luo Y, Beck B, Peatman E (2014b) Characterization and mucosal responses of interleukin 17 family ligand and receptor genes in channel catfish Ictalurus punctatus. Fish Shellfish Immunol. 38:47-55.

Xu Q, Li R, Monte MM, Jiang Y, Nie P, Holland JW, Secombes CJ, Wang T (2014). Sequence and expression analysis of rainbow trout CXCR2, CXCR3a and CXCR3b aids interpretation of lineage-specific conversion, loss and expansion of these receptors during vertebrate evolution. Dev Comp Immunol 45:201-13.

Zhang H, Shen B, Wu H, Gao L, Liu Q, Wang Q, Xiao J, Zhang Y (2014) Th17-like immune response in fish mucosal tissues after administration of live attenuated Vibrio anguillarum via different vaccination routes. Fish Shellfish Immunol 37:229-238.

\section{Figure legends:}

Fig. 1. Comparison of the gene organisation of IL-17A/F isoforms, IL-17N, IL17C and IL-17D from salmonids and other vertebrates. The gene organisations of salmonid IL-17A/F isoforms and IL-17N were predicted using the Spidey program based on the sequence information from Tables 2 and 3. The black and white boxes represent amino acid coding regions and untranslated regions within exons, respectively, and the black bars represent introns. The sizes (bp) of exons are numbered in the boxes and the intron phase is indicated under the bar. The organisation of IL-17A/F genes in fugu and humans were reported by Korenaga et al. (2010), and trout IL-17D by Kumari et al. (2009). The gene organisations of trout IL- 
17C1, IL-17C2 and IL-17D were extracted from genomic contigs (CCAF010020710, CCAF010017156 and CCAF010011045) and cDNA sequences (FM955453, FM955454 and AJ580843), respectively. Sequence data representing all other genes was extracted from ENSEMBL genes ENSDARG00000043933 (zebrafish IL17A/F1), ENSDARG00000043934 (zebrafish IL-17A/F2), ENSDARG00000041976 (zebrafish IL-17A/F3), ENSLOCG00000015957 (spotted gar IL-17A/F1), ENSLOCG00000015959 (spotted gar IL-17A/F2), ENSG00000124391 (human IL17C) and ENSG00000172458 (human IL-17D).

Fig. 2. Multiple alignment of IL-17A/F and IL-17N molecules. IL-17A/F and IL$17 \mathrm{~N}$ mature peptide sequences from selected $3 \mathrm{R}$ fish (including the $4 \mathrm{R}$ salmonids), 2R spotted gar (gar) and mammals (human and mouse) were aligned using ClustalW (Chenna et al. 2003) and manually adjusted. The conserved aa were shaded using BOXSHADE (V3.21). The (predicted) four core $\beta$-strands (1-4) and six conserved cysteine residues are marked above the alignment. The two pairs of cysteine residues that form two disulphide bonds between strand 2 and 4 are connected. Two somewhat conserved $\mathrm{N}$-glycosylation sites are indicated by down arrow heads below the alignment. A basic K/R rich region in IL-17A/F3 is highlighted by a bar. The amino acid residues across the second intron in the coding region of all the IL-17A/F genes are indicated by a down arrow and those across the third intron of IL-17A/F3 genes are indicated by an up arrow. The length (aa) of each mature peptide is indicated at the end of alignment. The accession numbers for sequences used in this alignment are given in Fig. 3. Note, the last 20 aa of salmon IL-17A/F3 was removed from the alignment.

Fig. 3. An unrooted phylogenetic tree of known fish IL-17 family members. The tree was constructed using amino acid multiple alignments and the neighbour-joining method within the MEGA6 program (Tamura et al. 2013). Node values represent percent bootstrap confidence derived from 10,000 replicates, and those at the roots of each clade are highlighted with a circle. The salmonid genes reported in this study are shaded. Tentative groupings of the fish IL-17 family members are indicated on the right. The spotted gar IL-17A/F1 and IL-17A/F2 were derived from Ensembl genes ENSLOCG00000015957 and ENSLOCG00000015959, respectively. The accession numbers of the molecules used are as follows: for IL-17A/F1 molecules K4PBM6 
(turbot), E3WEA7 (medaka), BAI82578 (fugu), I3J5T4 (tilapia) and Q5TKT4 (zebrafish); for IL-17A/F3 molecules E3WEA9 (medaka), I3IYE4 (tilapia), BAI82580 (fugu), W5U9A5 (catfish) and Q5TKT0 (zebrafish); for IL-17A/F2 molecules Q5TKT3 (zebrafish), BAI82579 (fugu), E3WEA8 (medaka) and I3J5T2 (tilapia); for IL-17N molecules E3WEB2 (medaka), XP_003459056 (tilapia) and D4AHP7 (fugu); for IL-17C molecules D4AHP4 (fugu C1) D4AHP5 (fugu C2), I3J8T3 (tilapia C1), I3J5W0 (tilapia C2), E3WEB0 (medaka), W5UD15 (catfish), F1QI25 (zebrafish), D4HTR8 (trout C1), D4HTR9 (trout C2); and for IL-17D molecules W5UD84 (catfish), Q5TKT1 (zebrafish), E3WEB1 (medaka D1), H2MCF1 (medaka D2), D4AHP6 (fugu), B5X8Q6 (salmon) and Q70I20 (trout).

Fig. 4. Diagram to show gene synteny at the IL-17A/F loci in vertebrates. The synteny was analysed using Genomicus v75.01 (Louis et al. 2013) using the gene order in the spotted gar IL-17A/F1/2 locus on chromosome (Chr) LG1 as reference. The syntenically conserved orthologs or gene blocks are shown in matching colours. The arrows indicate the transcriptional direction.

Fig. 5. Constitutive expression of IL-17A/F isoforms and $\mathrm{L}-17 \mathrm{~N}$ in vivo in Atlantic salmon. The transcript expression level of IL-17A/F1a, 1b, 2a, 2b and 3, and IL-17N was determined by real time RT-PCR in 15 tissues from six Atlantic salmon (average weight, $34 \mathrm{~g}$ ). The tissues were ordered according to the average expression levels of trout IL-17A/F1a from the lowest to highest. The expression level for each gene is presented relative to the expression level of EF-1 $\alpha$. The results represent the average + SEM. The ratios of the expression levels between IL-17A/F1a and IL17A/F1b, and between IL-17A/F2a and IL-17A/F2b are shown above the bars when significantly different $(\mathrm{p}<0.05)$ by a Paired-Sample t-test. HK=head kidney, CK=caudal kidney.

Fig. 6. Modulation of the expression of Atlantic salmon IL-17A/F isoforms and IL-17N in HK cells by immune stimulants. Salmon HK cells were stimulated with LPS $(25 \mu \mathrm{g} / \mathrm{ml})$, poly I:C (50 $\mu \mathrm{g} / \mathrm{ml})$, PHA $(10 \mu \mathrm{g} / \mathrm{ml})$ and PMA $(0.1 \mu \mathrm{g} / \mathrm{ml})$ for $4 \mathrm{~h}, 8$ $\mathrm{h}$ and $24 \mathrm{~h}$. The transcript level was normalised by that of EF-1 $\alpha$ and expressed as a fold change that was calculated as the average expression level of stimulated samples 
divided by that of the time-matched controls. The mean+SEM of four fish is shown. The p-values of a Paired-Sample $T$ test between stimulated samples and their time matched controls are shown above the bars as: ${ }^{*} p<0.05,{ }^{* *} \mathrm{p} \leq 0.01$ and ${ }^{* * *} \mathrm{p} \leq 0.001$.

Fig. 7. Confirmation of the bioactivities of rainbow trout recombinant cytokines in Atlantic salmon HK cells, assessed by marker gene expression. Salmon HK cells were stimulated with trout recombinant IL-1 $\beta(20 \mathrm{ng} / \mathrm{ml})$, IFN- $\gamma(20 \mathrm{ng} / \mathrm{ml})$, TNF- $\alpha 3(10 \mathrm{ng} / \mathrm{ml})$, IL-2 (200 ng/ml) and IL-21 $(100 \mathrm{ng} / \mathrm{ml})$, for $4 \mathrm{~h}, 8 \mathrm{~h}$ and $24 \mathrm{~h}$ and gene expression analysis was performed as in Figure 5. The expression of marker genes examined are IL-1 $\beta 1$ and TNF- $\alpha 1$ (A) for IL-1 $\beta$; CATH2 and IL-6 (B) for IL-6; TNF- $\alpha 1$ and CATH1 (C) for TNF- $\alpha 3$; $\gamma$ IP and IL-12 p35a1 subunit (D) for IFN- $\gamma$; and $\gamma$ IP and IFN- $\gamma(\mathbf{E}$ and $\mathbf{F})$ for IL-2 and IL-21. The mean+SEM of four fish is shown. The p-values of a Paired-Sample $T$ test between stimulated samples and their time matched controls are shown above the bars as: ${ }^{*} \mathrm{p}<0.05,{ }^{* *} \mathrm{p} \leq 0.01$ and ${ }^{* * *} \mathrm{p} \leq 0.001$.

Fig. 8. Modulation of the expression of Atlantic salmon IL-17A/F isoforms and IL-17N in HK cells by cytokines. Salmon HK cells were stimulated with trout recombinant IL-1 $\beta(20 \mathrm{ng} / \mathrm{ml}), \mathrm{IFN}-\gamma(20 \mathrm{ng} / \mathrm{ml}), \mathrm{TNF}-\alpha 3(10 \mathrm{ng} / \mathrm{ml}), \mathrm{IL}-2(200$ $\mathrm{ng} / \mathrm{ml})$ and IL-21 (100 ng/ml), for $4 \mathrm{~h}, 8 \mathrm{~h}$ and $24 \mathrm{~h}$ and gene expression analysis was performed as in Figure 5. The mean+SEM of four fish is shown. The p-values of a Paired-Sample $\mathrm{T}$ test between stimulated samples and their time matched controls are shown above the bars as: ${ }^{*}<0.05$ and ${ }^{* *} \mathrm{p} \leq 0.01$.

Fig. 9. Modulation of the expression of rainbow trout IL-17A/F isoforms and IL$17 \mathrm{~N}$ in gills, spleen and HK by vaccination and bacterial challenge. Two groups of fish were ip injected with either AquaVac ${ }^{\mathrm{TM}} \operatorname{ERM}(\boldsymbol{\square})$ or PBS ( $\left.\square\right)$ as control. The fish were challenged 10 weeks later by ip injection of $Y$. ruckeri $\left(0.5 \mathrm{ml} /\right.$ fish, $1 \times 10^{6}$ cfu/ml; YR group) or injected with $0.5 \mathrm{ml}$ of PBS as control (PBS group). The fish from each group were killed and gills, spleen and HK were collected for total RNA extraction. The gene expression analysis was performed as in Figure 5. The change of expression level was expressed as arbitrary units where one unit equals the average expression level in the PBS injected control group at day 1 in each tissue. The means + SEM of four fish are shown. The expression levels between different groups of the 
same tissue are statistically significant $(\mathrm{p}<0.05)$ where letters over the bars are different, as determined by one way-ANOVA. When the letter "a" occurs by itself it has been removed from the bars for clarity. 


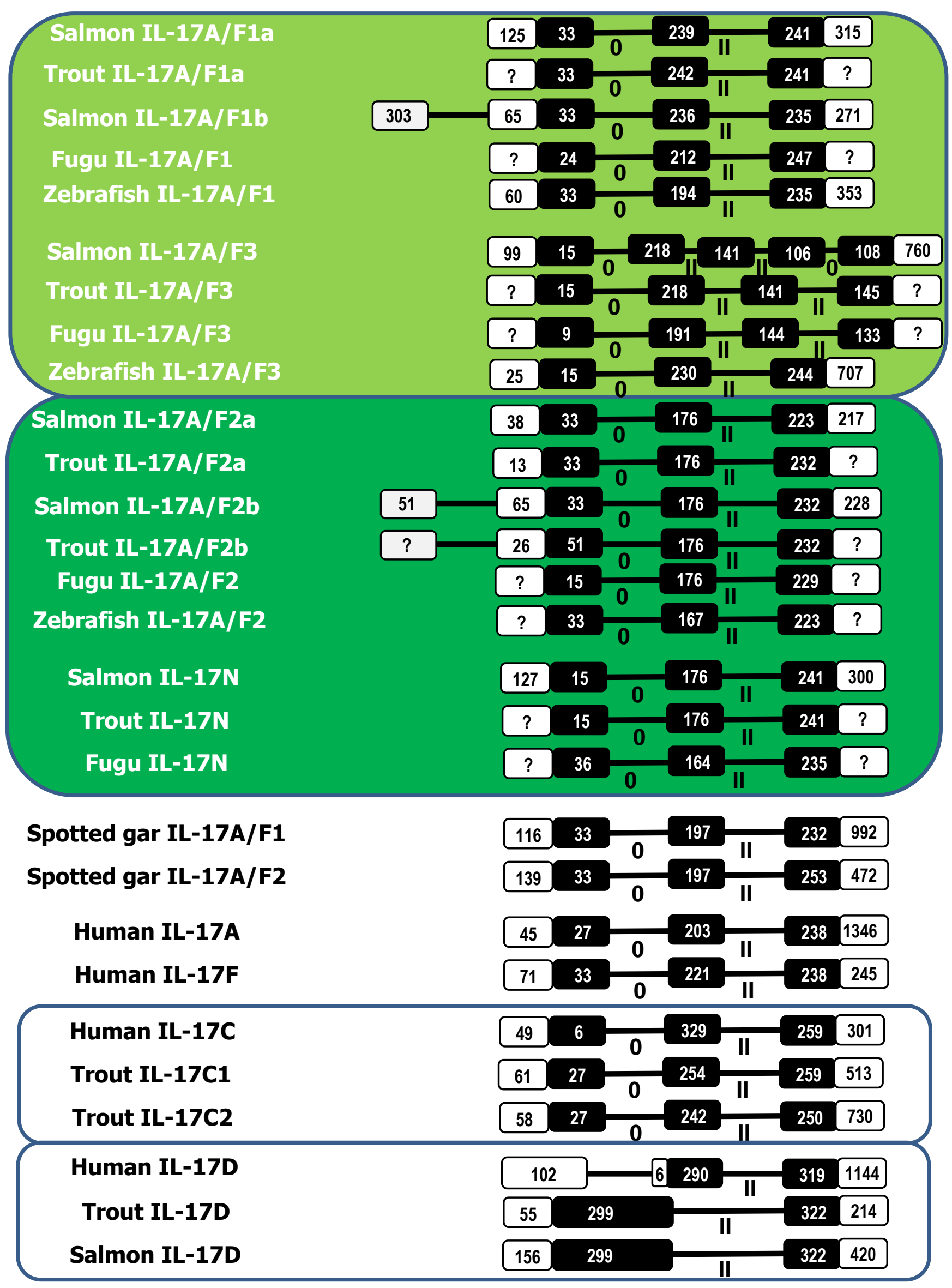




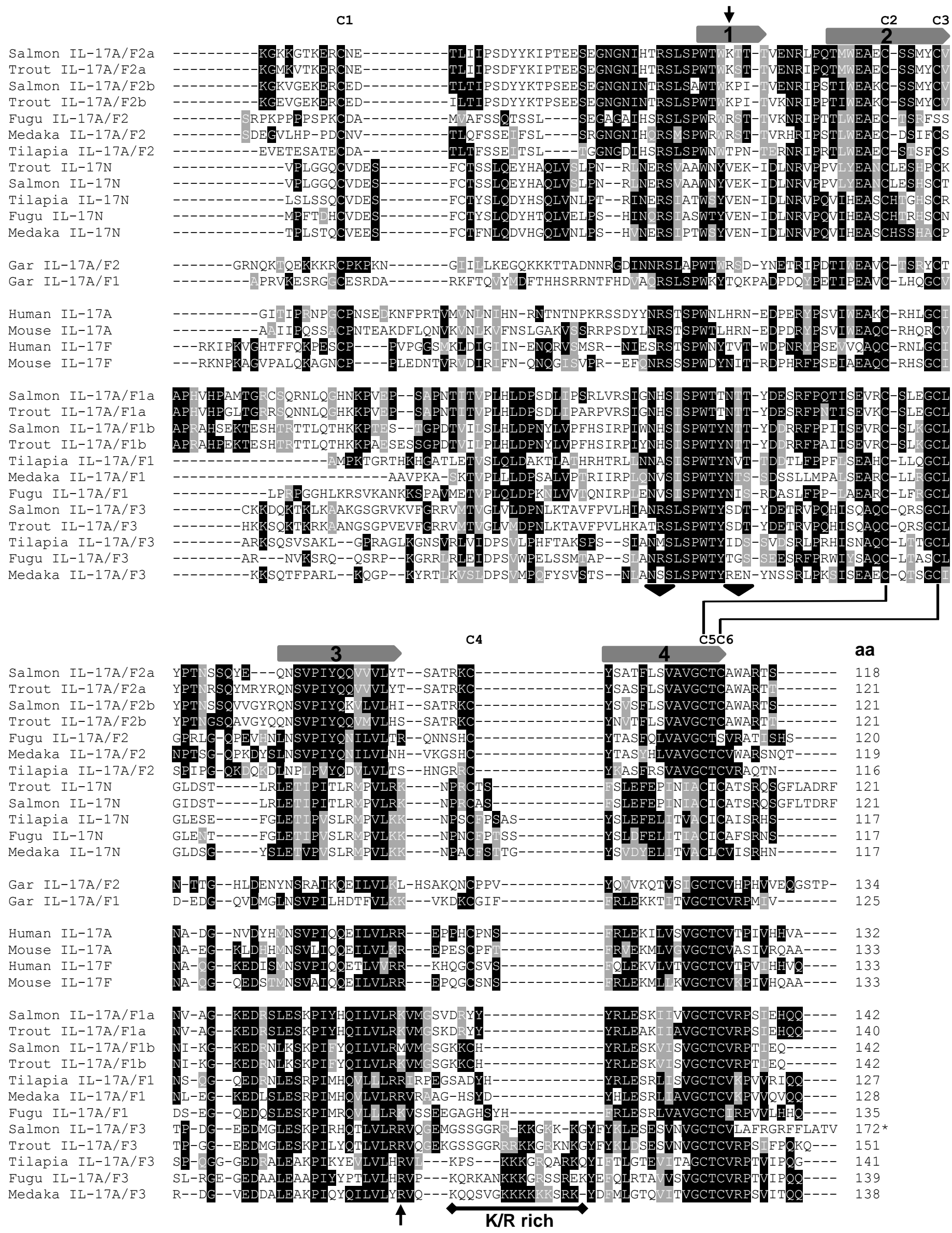




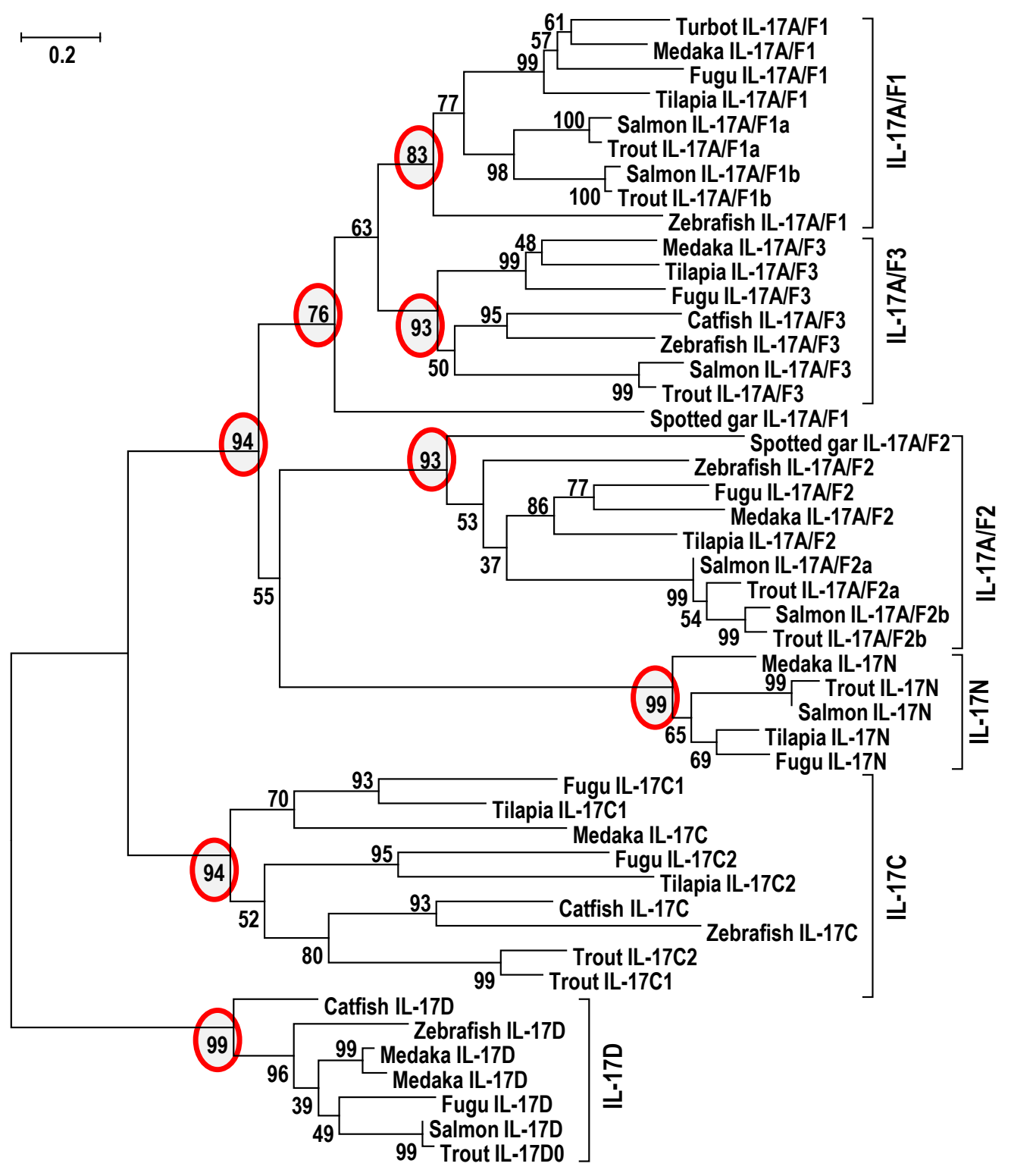




$\begin{array}{ccccccc}\text { Human } & \text { Chcken } & \text { Spotted gar } & \text { Tilapia } & \text { Tilapia } & \text { Zebrafish } & \text { Zebrafish } \\ \text { Ch6 } & \text { Ch4 } & \text { LG1 } & \text { GL831133 } & \text { GL831143 } & \text { Ch17 } & \text { Ch20 }\end{array}$
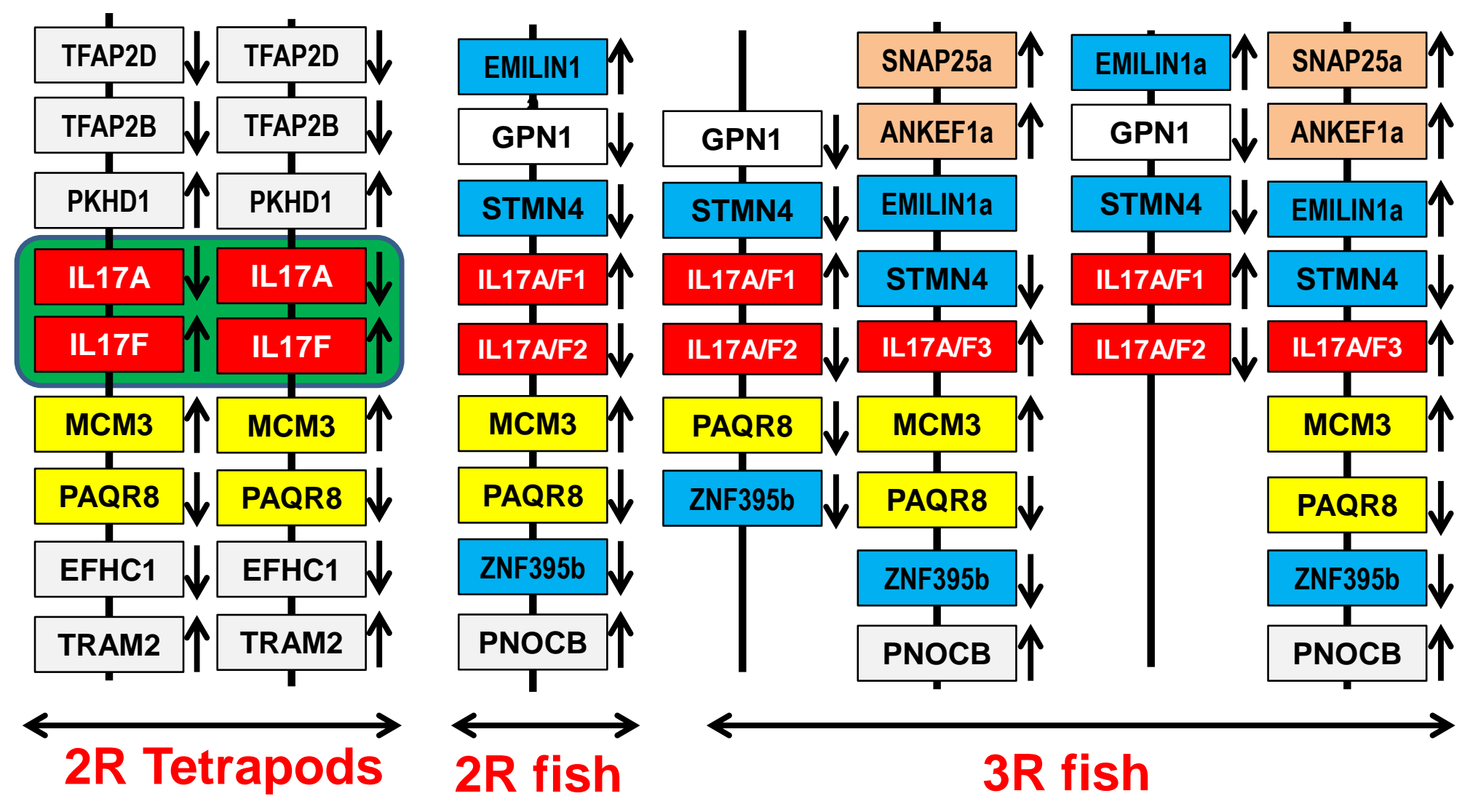


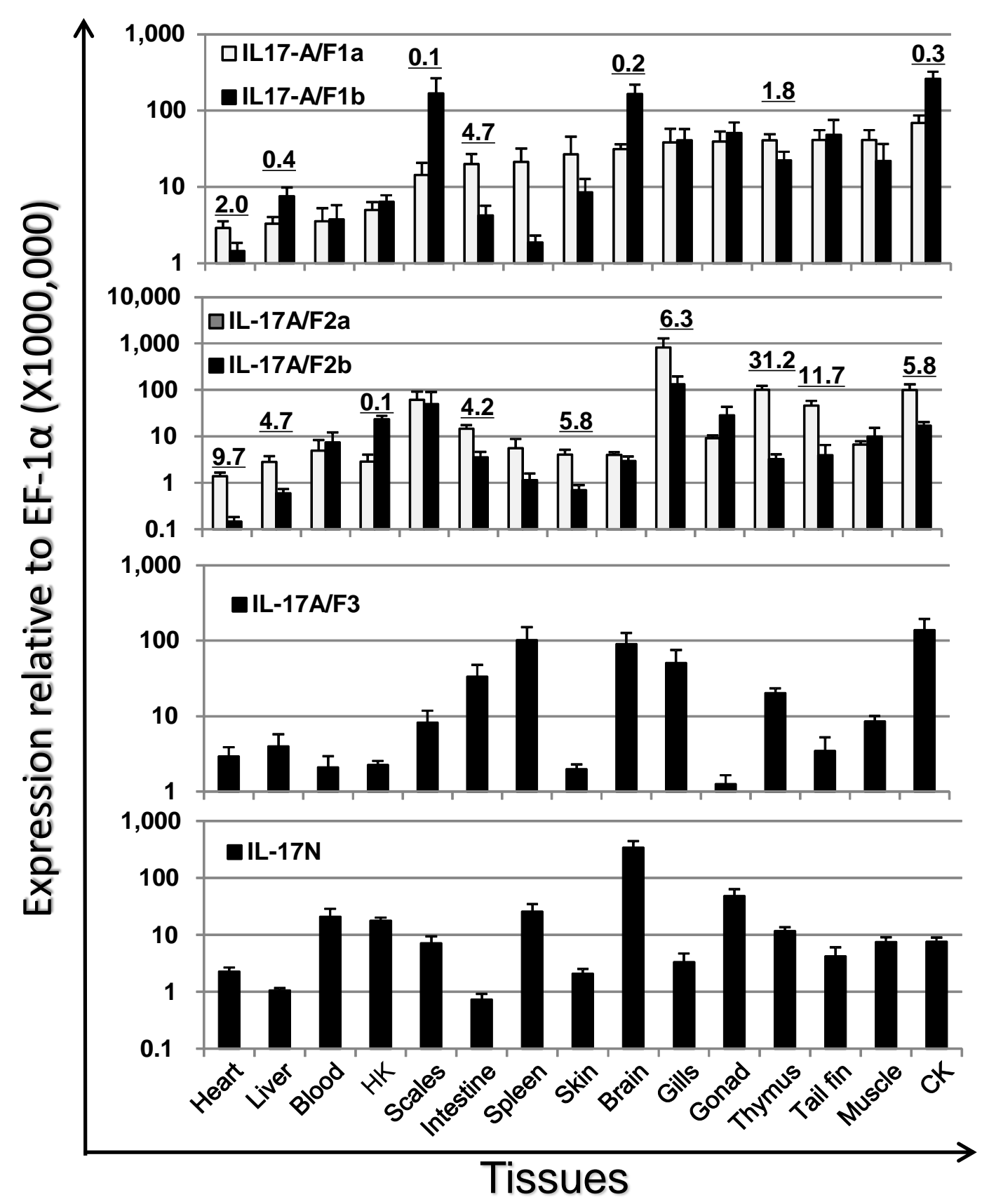


Fig. 6.

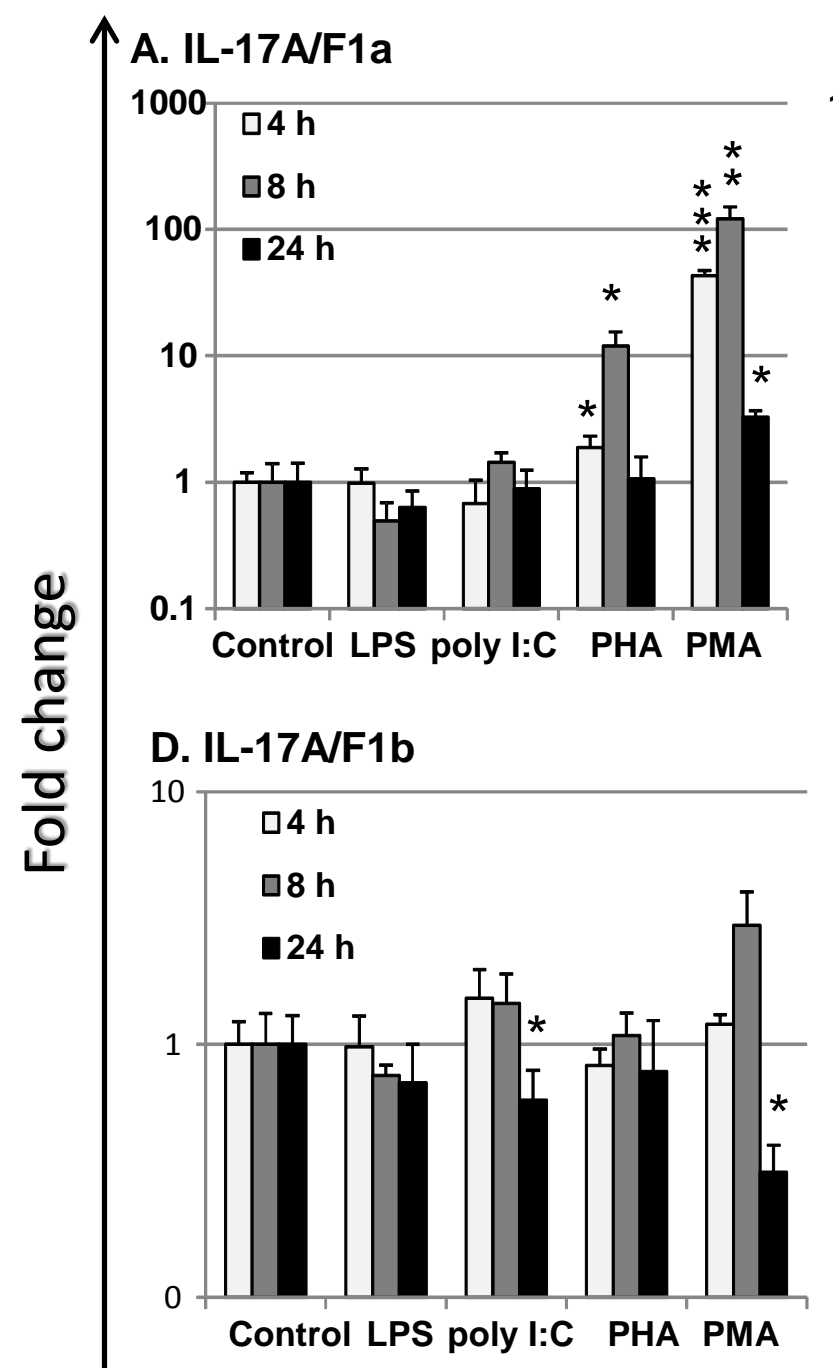

\section{B. IL-17A/F2a}

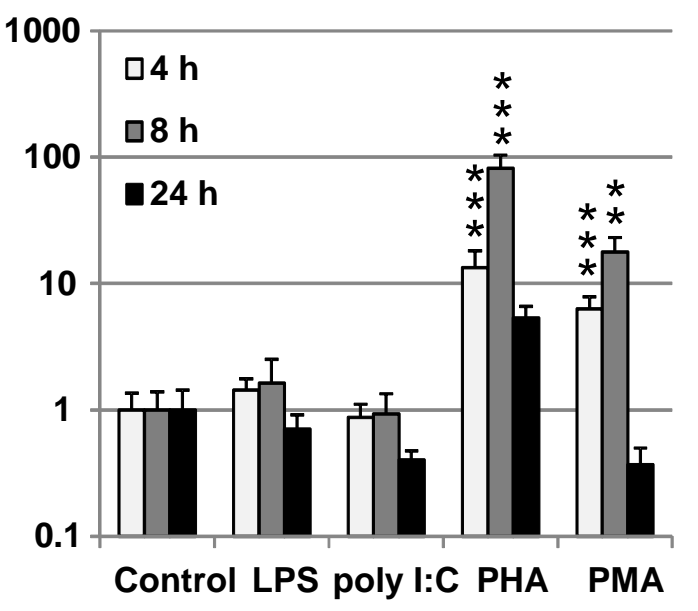

\section{E. IL-17A/F2b}

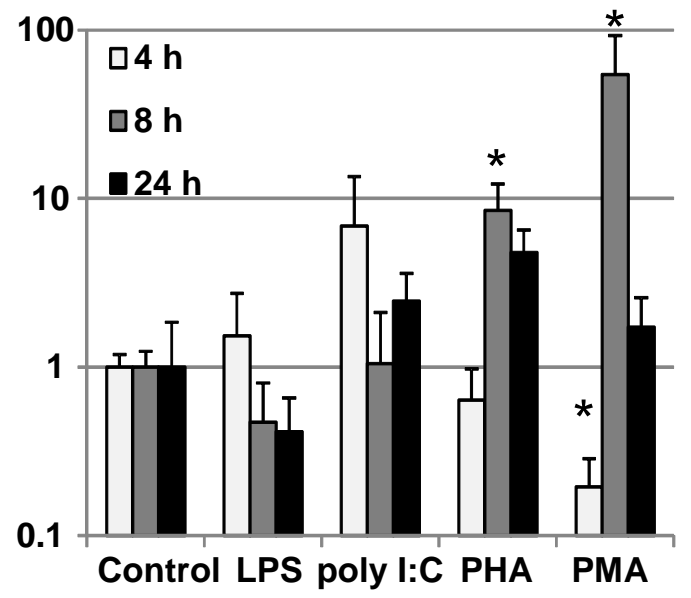

\section{IL-17A/F3}

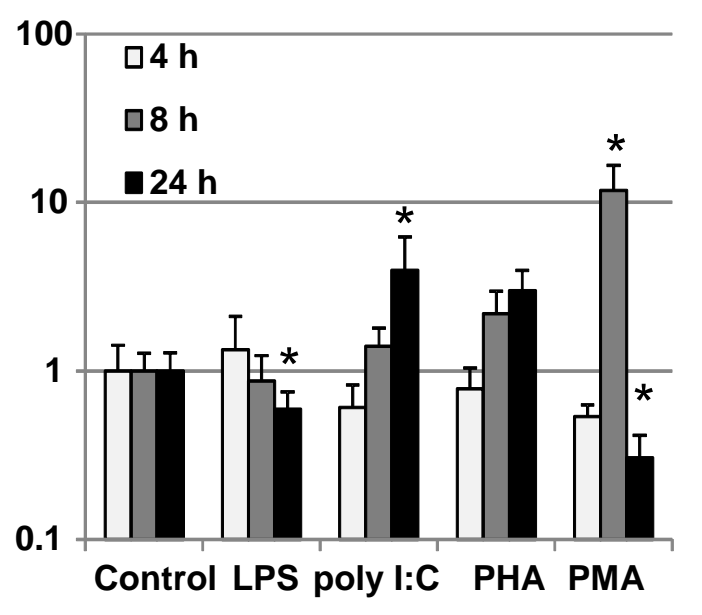

\section{F. IL-17N}

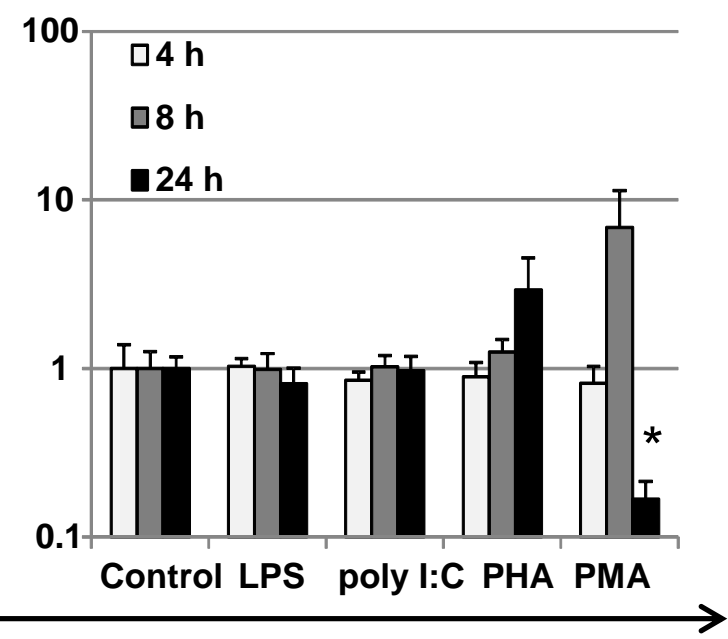

Treatment 
Fig. 7.

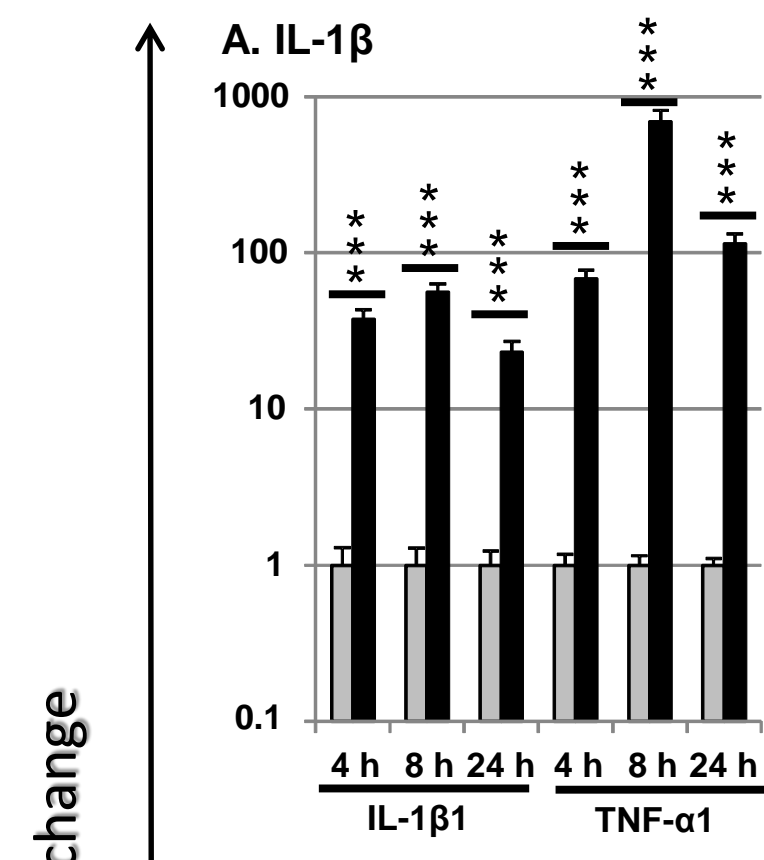

D. IFN- $\gamma$

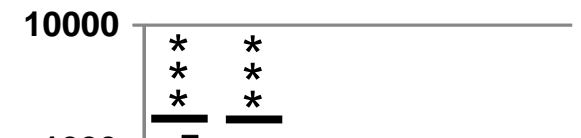

$1000 \frac{*}{\pi} \frac{*}{\pi}$
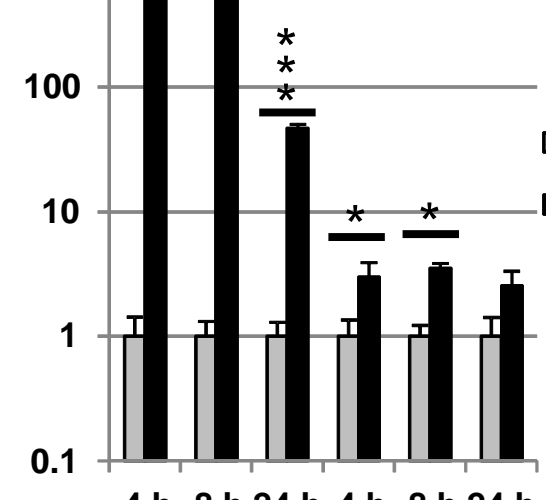

4 h 8 h 24 h 4 h 8 h 24 h

$\gamma$ IP IL-12p35a1
B. IL-6

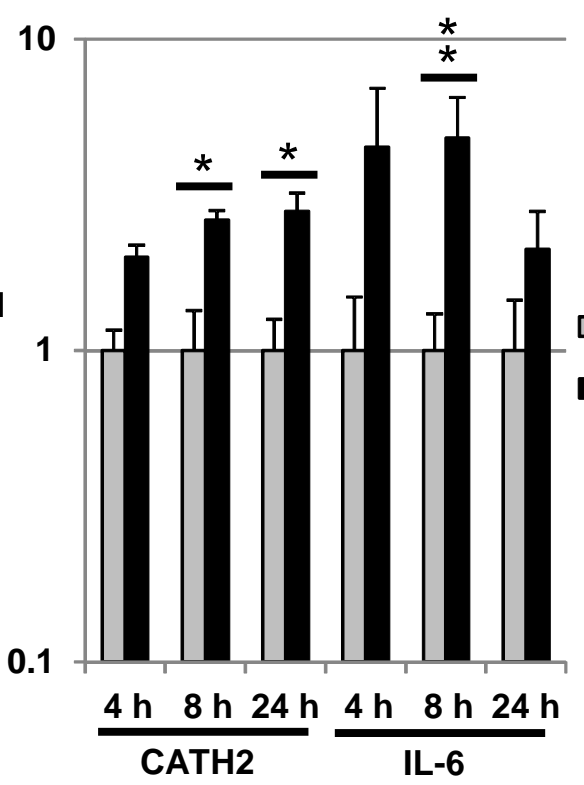

E. IL-2

10

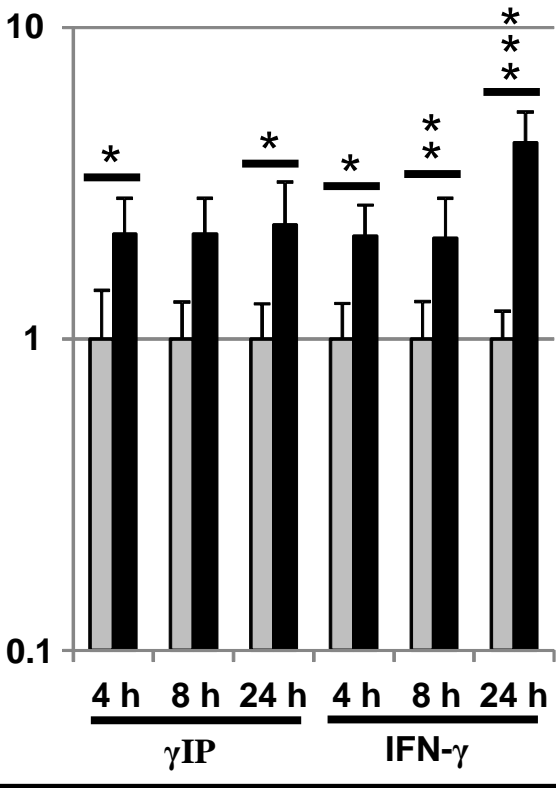

C. TNF- $\alpha 3$

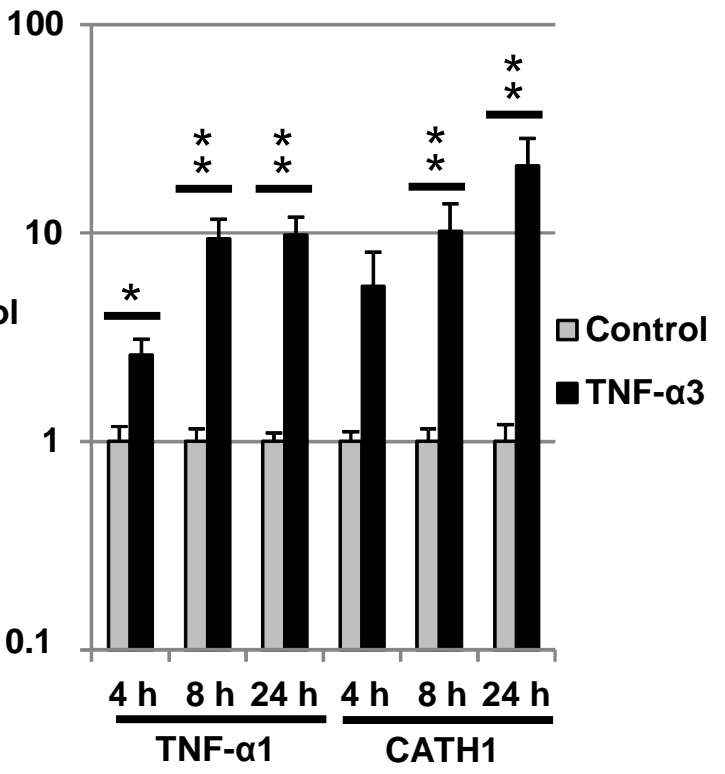

F. IL-21

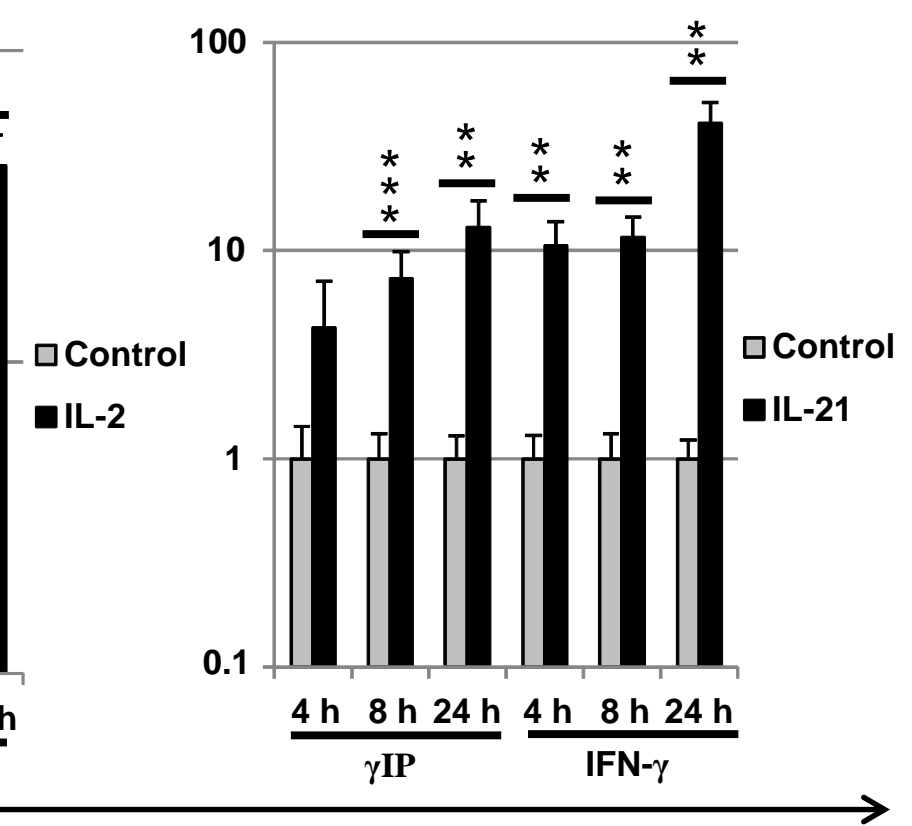

Time and gene 
Fig. 8.
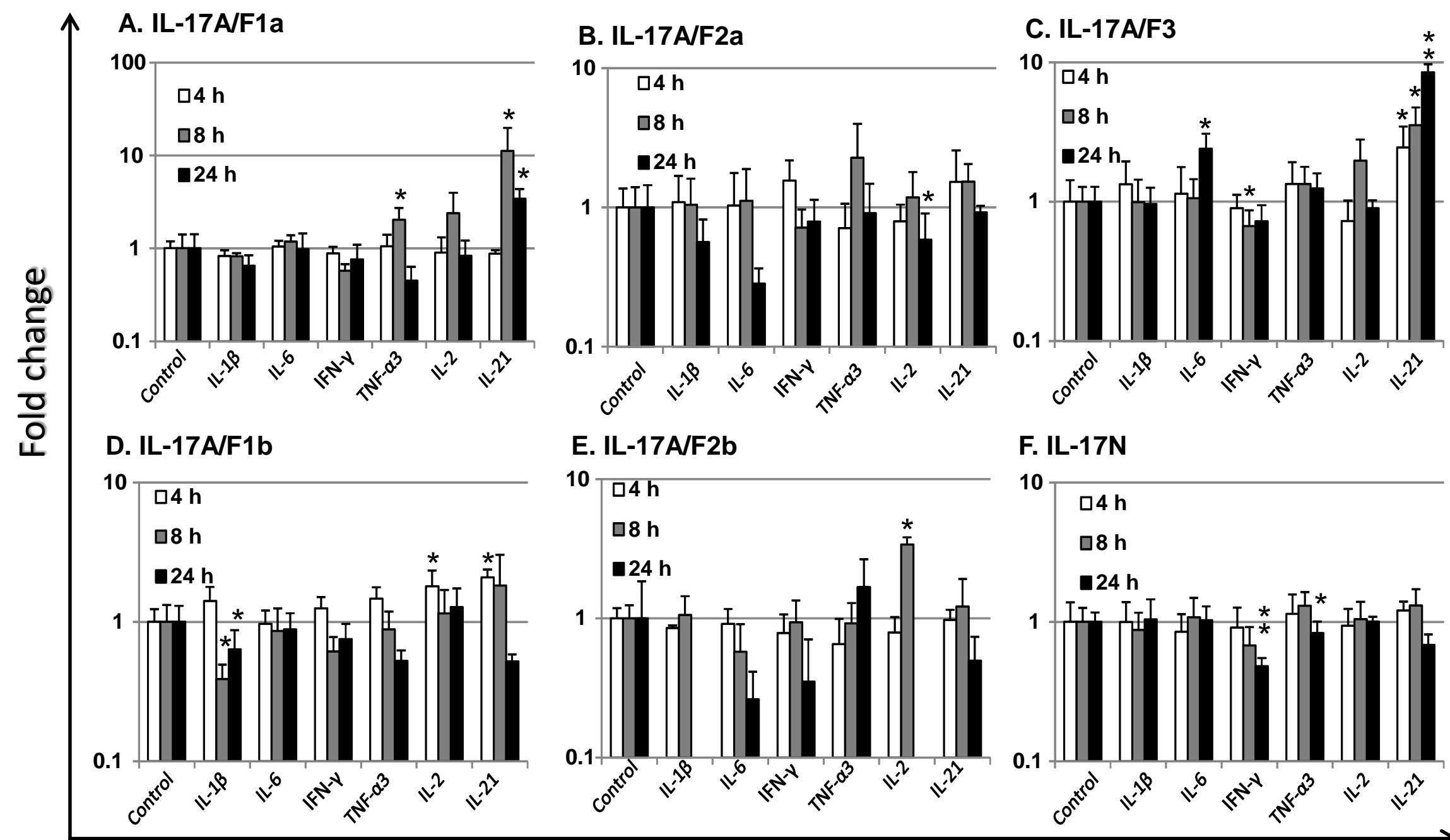

E. IL-17A/F2b

\section{F. IL-17N}
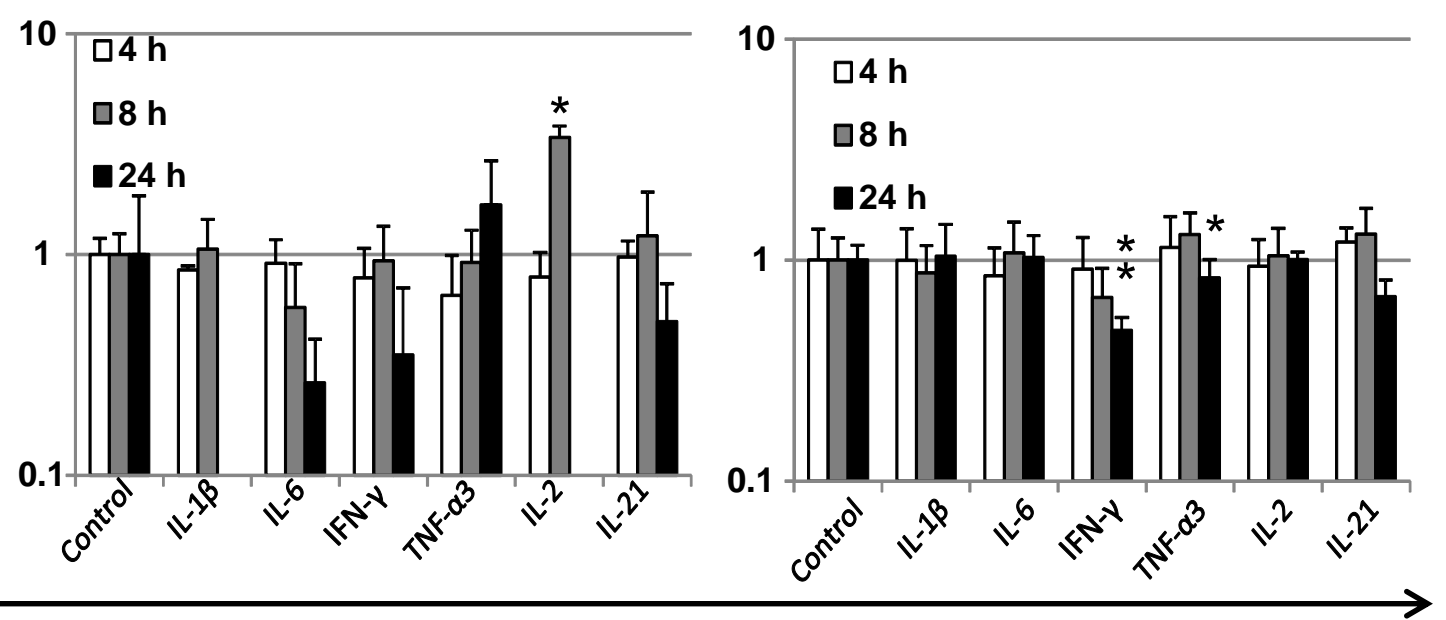

Treatment 


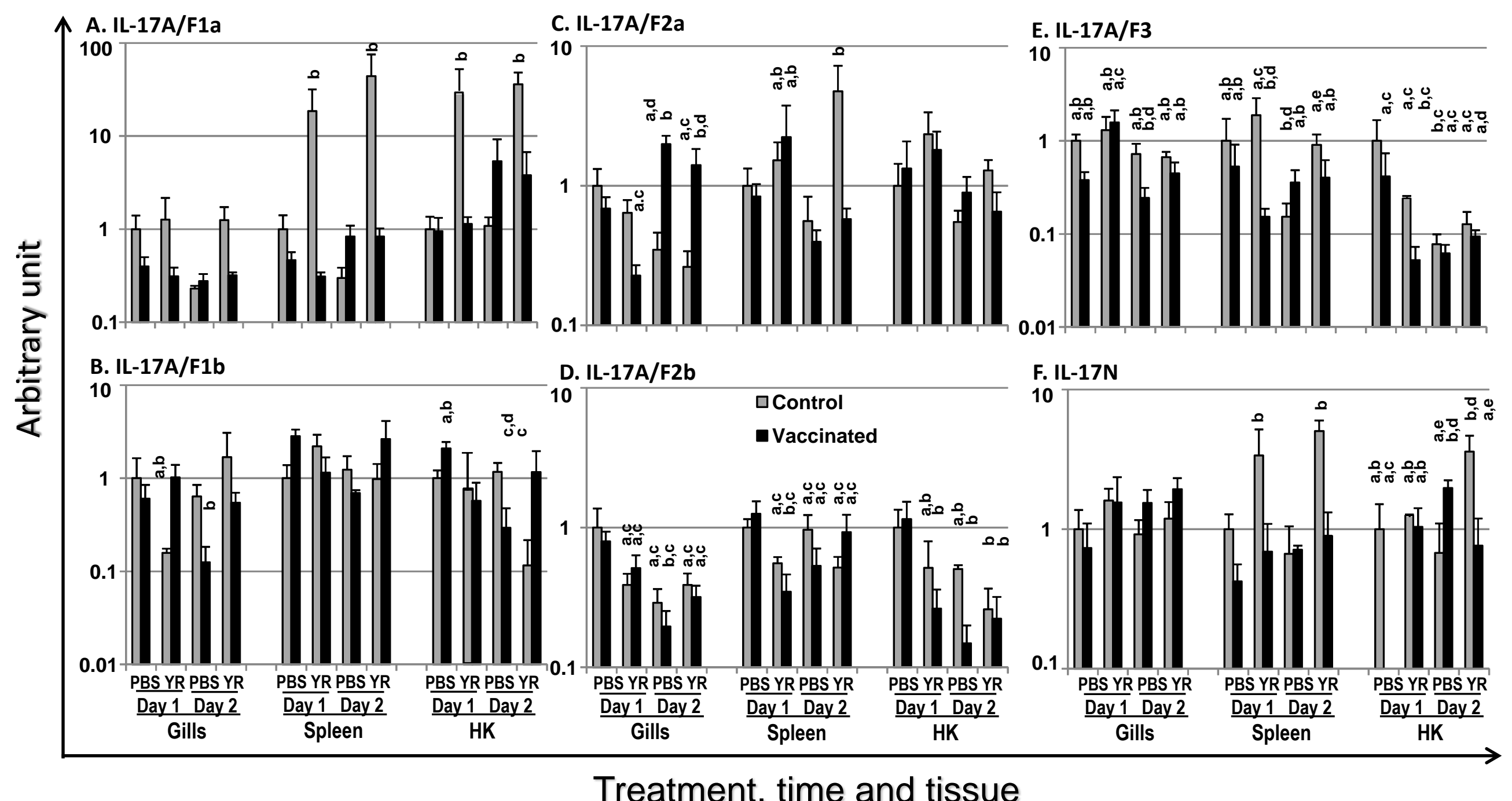

\section{IL-17A/F2a}

10

Treatment, time and tissue
E. IL-17A/F3

F. IL-17N 
Table 1 Primers used for PCR cloning and real-time PCR analysis of gene expression

\begin{tabular}{|c|c|c|c|}
\hline Gene & Primer name & Sequence (5' to 3') & Application \\
\hline \multirow[t]{6}{*}{ Salmon IL-17A/F1a } & S1aF1 & ATCCAGCGATGACAGGGAGAT & 3'-RACE \\
\hline & S1aF2 & GCTCACAGAGAAACCTTCAGGG & 3'-RACE \\
\hline & S1aR1 & GACTCCAGCCGGTAGTAGTATCTGTC & 5'-RACE \\
\hline & S1aR2 & GAGAGCACCTGACCTCCGAGAT & 5'-RACE \\
\hline & S1aF & ACACACGGACCACACTCCAGAC & Real-time PCR \\
\hline & S1aR & GCGTCGATCGTCATAGGTAGTGTTGTA & Real-time PCR \\
\hline \multirow[t]{6}{*}{ Salmon IL-17A/F1b } & S1bF1 & CCCATTCAGAGAAGACAGAGAGCC & 3'-RACE \\
\hline & S1bF2 & CACACGGACCACACTCCAGAC & 3'-RACE \\
\hline & S1bR1 & ACACAGGTGCAGCCCACTGA & 5'-RACE \\
\hline & S1bR2 & GAGAGCACCTGACCTCCGAGAT & 5'-RACE \\
\hline & S1bF & TGCTCACAGAGAAACCTTCAGGG & Real-time PCR \\
\hline & S1bR & GGGACTCATCATAGGTGGTGTTGGT & Real-time PCR \\
\hline \multirow[t]{6}{*}{ Salmon IL-17A/F2a } & S2aF1 & GACGGACAGGGATCAGAGATGG & 3'-RACE \\
\hline & S2aF2 & GGCAAAAGGAAAGAAGGGGAC & 3'-RACE \\
\hline & S2aR1 & CACTTCCTGGTGGCTGAAGTGTA & 5'-RACE \\
\hline & S2aR2 & GCTGTTGGTGGGGTAGACACA & 5'-RACE \\
\hline & S2aF & ACCCTGGACCTGGAAAACCAC & Real-time PCR \\
\hline & S2aR & GCTGAAGTGTAGAGTACCACGACCTG & Real-time PCR \\
\hline \multirow[t]{6}{*}{ Salmon IL-17A/F2b } & $\mathrm{S} 2 \mathrm{bF} 1$ & CAGAGATGGAGCTCAAAAACAACAC & 3'-RACE \\
\hline & S2bF2 & GCAAAGGGAAGGTGGGGGA & 3'-RACE \\
\hline & S2bR1 & TGGCTGAGATATGGAGCACCAG & 5'-RACE \\
\hline & S2bR2 & GCTGTTGGTGGGGTAGACACA & 5'-RACE \\
\hline & $\mathrm{S} 2 \mathrm{bF}$ & GCAAAGGGAAGGTGGGGGA & Real-time PCR \\
\hline & $\mathrm{S} 2 \mathrm{bR}$ & GGTTCTCCACTGTAATGGGTTTCCA & Real-time PCR \\
\hline \multirow[t]{6}{*}{ Salmon IL-17A/F3 } & S3F1 & CGCTGGACGGATGTAAGAAAGACC & 3'-RACE \\
\hline & S3F2 & GGCTCCGGACGAGTCAAGG & 3'-RACE \\
\hline & S3R1 & CAACCCCATGTCCTCTTCTCC & 5'-RACE \\
\hline & S3R2 & TGTTGAGGGACTCGGGTCTC & 5'-RACE \\
\hline & S3F & CTGGTGCTGGGTCTGATCATGT & Real-time PCR \\
\hline & S3R & GGTCTCATCGTATGTGTCGCTGTATG & Real-time PCR \\
\hline \multirow[t]{6}{*}{ Salmon IL-17N } & S4F1 & CATGCGTCAGTGCCTGTGTG & 3'-RACE \\
\hline & S4F2 & AGCTAGTCAGCCTGCCCAACC & 3'-RACE \\
\hline & S4R1 & TCCTCAGCACGGGCATCCT & 5'-RACE \\
\hline & S4R2 & TACCCGTACAGGAGTGGCTTTC & 5'-RACE \\
\hline & S4F & CCGCCTGGAACTACGTGGAAA & Real-time PCR \\
\hline & S4R & GCTTTGTCTGGAAGTGGCGCA & Real-time PCR \\
\hline \multirow[t]{2}{*}{ Trout IL-17A/F1a } & T1aF1 & CCAGAACACAGCAGCAGAAAAAGAC & PCR cloning \\
\hline & T1aR1 & AATGTGGGGATCAAACCTACAACC & PCR cloning \\
\hline \multirow[t]{2}{*}{ Trout IL-17A/F1b } & T1F1 & AGGACCACAACACAGCAACAGA & PCR cloning \\
\hline & T1R1 & CATGTAGGGATTGAGCCTTCAACC & PCR cloning \\
\hline \multirow[t]{2}{*}{ Trout IL-17A/F2b } & T2bF1 & CGCACCTTCCTCCACTCAAG & PCR cloning \\
\hline & T2bR1 & AGTCAATTCTTCTGGCTTTGTGGG & PCR cloning \\
\hline \multirow[t]{2}{*}{ Trout IL-17A/F3 } & T3F1 & GCAACGTTTCACTCTGAAGAGACAG & PCR cloning \\
\hline & T3R1 & CTGGGGAAGTAGACAAAGGGCATC & PCR cloning \\
\hline \multirow[t]{2}{*}{ Trout IL-17N } & T4F1 & ACCCACAGCACAGCAGAGACAGA & PCR cloning \\
\hline & T4R1 & GATGTCATTGTGGCAAACGACTAAC & PCR cloning \\
\hline \multirow[t]{2}{*}{ EF-1a } & EF-1aF & CAAGGATATCCGTCGTGGCA & Real-time PCR \\
\hline & EF-1aR & ACAGCGAAACGACCAAGAGG & Real-time PCR \\
\hline \multirow[t]{2}{*}{ Salmon IL-1 $\beta$} & $\mathrm{IL}-1 \beta \mathrm{F}$ & GCTGGAGAGTGCTGTGGAAGAAC & Real-time PCR \\
\hline & $\mathrm{IL}-1 \beta \mathrm{R}$ & CGTAGACAGGTTCAAATGCACTTTGTG & Real-time PCR \\
\hline \multirow[t]{2}{*}{ Salmon TNF-a1 } & TNF1F & ACTGGCAACGATGCAGGACAA & Real-time PCR \\
\hline & TNF1R & GCGGTAAGATTAGGATTGTATTCACCCTCT & Real-time PCR \\
\hline \multirow[t]{2}{*}{ Salmon $\gamma \mathrm{IP}$} & $\gamma \mathrm{IPF}$ & TCATCAGCTTCCTGGCCTGTC & Real-time PCR \\
\hline & $\gamma \mathrm{IPR}$ & TTCTCCGTTCTTCAGAGTGACAATGAT & Real-time PCR \\
\hline Salmon CATH1 & CATH1F & TGTCCTCTGAAGAAAAATGGGAAACT & Real-time PCR \\
\hline & CATH1R & TCTTCTTGTCCGAATCTTCTGCAT & Real-time PCR \\
\hline Salmon CATH2 & CATH2F & CCTCTGAAGAAAAATGGGAAACG & Real-time PCR \\
\hline & CATH2R & CCTCTTCTTGTCCGAATCTTCTGAGT284 & Real-time PCR \\
\hline Salmon IL-6 & IL-6F & GAAGTGGGAGCAAATTATCAAGATGC & Real-time PCR \\
\hline & IL-6R & GCAGACATGCCTCCTTGTTGGT & Real-time PCR \\
\hline Salmon IFN- $\gamma$ & $\mathrm{IFN}-\gamma \mathrm{F}$ & GATGGGCTGGATGACTTTAGGATG & Real-time PCR \\
\hline & IFN- $\gamma \mathrm{R}$ & CCTCCGCTCACTGTCCTCAAA & Real-time PCR \\
\hline Salmon IL-12p35a1 & P35a1F & GAGTTTGGAAACTGAGAAATGCGG & Real-time PCR \\
\hline & P35a1R & GACCAGAGCATCTTGTGTTCCTGTC & Real-time PCR \\
\hline
\end{tabular}


Table 2 Summary of sequence analysis of Atlantic salmon IL-17A/F isoforms and IL-17N

\begin{tabular}{|c|c|c|c|c|c|c|c|}
\hline & Features & Salmon IL-17A/F1a & Salmon IL-17A/F1b & Salmon IL-17A/F2a & Salmon IL-17A/F2b & Salmon IL-17A/F3 & Salmon IL-17N \\
\hline \multirow{5}{*}{ 竞 } & GenBank ID ${ }^{1}$ & KJ921970 & KJ921971 & KJ921972 & KJ921973 & KJ921974 & KJ921975 \\
\hline & Length (bp) & 975 & 1168 & 715 & 813 & 1476 & 878 \\
\hline & ORF (bp) & 513 & 504 & 432 & 459 & 582 & 432 \\
\hline & Upstream AUG ${ }^{2}$ & 0 & 5 & 0 & 1 & 0 & 0 \\
\hline & ATTTA motif 3 & 4 & 3 & 2 & 2 & 2 & 2 \\
\hline \multirow{3}{*}{ 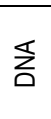 } & GenBank ID ${ }^{1}$ & AGKD01066665 & AGKD01004084 & AGKD01030631 & AGKD01100860 & AGKD01099448 & AGKD01056990 \\
\hline & No. of Exons/Introns & $3 / 2$ & $4 / 3$ & $3 / 2$ & $4 / 3$ & $5 / 4$ & $3 / 2$ \\
\hline & No. of Coding exons & 3 & 3 & 3 & 3 & 5 & 3 \\
\hline \multirow{5}{*}{ 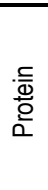 } & Full length (aa) & 170 & 167 & 143 & 152 & 193 & 143 \\
\hline & Signal peptide (aa) & 28 & 27 & 25 & 31 & 21 & 22 \\
\hline & Mature peptide (aa) & 142 & 140 & 118 & 121 & 172 & 121 \\
\hline & $\mathrm{MM} / \mathrm{pl}^{4}$ & $16.00 / 8.68$ & $16.07 / 9.54$ & $13.38 / 8.25$ & $13.54 / 8.77$ & $19.29 / 9.92$ & $13.58 / 5.64$ \\
\hline & N-glyco- sites ${ }^{5}$ & 2 & 2 & 2 & 1 & 1 & 0 \\
\hline
\end{tabular}

\section{Notes}

1 The accession number in GenBank.

2 Number of AUGs before the main ORF in the 5'-UTR.

3 Number of ATTTA motifs in the 3'-UTR.

4 Theoretical molecular weight $(\mathrm{kDa})$ and $\mathrm{pI}$ of the predicted mature peptides.

5 Potential N-glycosylation sites. 
Table 3 Summary of sequence analysis of rainbow trout IL-17A/F isoforms and IL-17N

\begin{tabular}{|c|c|c|c|c|c|c|c|}
\hline & Features & Trout IL-17A/F1a & Trout IL-17A/F1b & Trout IL-17A/F2a & Trout IL-17A/F2b & Trout IL-17A/F3 & Trout IL-17N \\
\hline \multirow{3}{*}{ 辛 } & GenBank ID ${ }^{1}$ & KJ921977 & KJ921978 & AJ580842 & KJ921979 & KJ921980 & KJ921981 \\
\hline & Length (bp) & 718 & 655 & 694 & 657 & 1011 & 723 \\
\hline & ORF (bp) & 516 & 510 & 441 & 480 & 519 & 432 \\
\hline \multirow{3}{*}{ 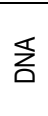 } & GenBank ID ${ }^{1}$ & CCAF010125208 & CCAF010087661 & CCAF010103911 & CCAF010090836 & CCAF010109336 & CCAF010069491 \\
\hline & No. of Exons/Introns & $3 / 2$ & $?$ & $3 / 2$ & $4 / 3$ & $4 / 3$ & $3 / 2$ \\
\hline & No. of Coding exons & 3 & $?$ & 3 & 3 & 4 & 3 \\
\hline \multirow{5}{*}{ 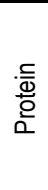 } & Full length (aa) & 171 & 169 & 146 & 159 & 172 & 143 \\
\hline & Signal peptide (aa) & 29 & 27 & 25 & 38 & 21 & 22 \\
\hline & Mature peptide (aa) & 142 & 142 & 121 & 121 & 151 & 121 \\
\hline & $\mathrm{MM} / \mathrm{pl}^{2}$ & $15.86 / 9.16$ & $16.21 / 9.49$ & 13.94/8.96 & $13.55 / 8.25$ & $16.86 / 10.10$ & $13.61 / 6.13$ \\
\hline & $\mathrm{N}$-glycosylation sites ${ }^{3}$ & 2 & 2 & 2 & 2 & 1 & 0 \\
\hline
\end{tabular}

\section{Notes}

1 Trout IL-17A/F2a was reported by Monte et al (2013).

2 Theoretical molecular weight $(\mathrm{kDa})$ and $\mathrm{pI}$ of the predicted mature peptides.

3. Potential N-glycosylation sites. 
